NBER WORKING PAPER SERIES

\title{
BAD CREDIT, NO PROBLEM? CREDIT AND LABOR MARKET CONSEQUENCES OF BAD CREDIT REPORTS
}

\author{
Will Dobbie \\ Paul Goldsmith-Pinkham \\ Neale Mahoney \\ Jae Song \\ Working Paper 22711 \\ http://www.nber.org/papers/w22711 \\ NATIONAL BUREAU OF ECONOMIC RESEARCH \\ 1050 Massachusetts Avenue \\ Cambridge, MA 02138 \\ October 2016
}

We are extremely grateful to Gerald Ray and David Foster at the Social Security Administration for their help and support. We also thank Orley Ashenfelter, Emily Breza, Hank Farber, Alex Mas, Jon Petkun, Isaac Sorkin, Eric Zwick, and numerous seminar participants for helpful comments and suggestions. Katherine DiLucido and Yin Wei Soon provided excellent research assistance. The views expressed are those of the authors and do not necessarily reflect those of the Federal Reserve Bank of New York, the Federal Reserve System, the Social Security Administration, or the National Bureau of Economic Research.

NBER working papers are circulated for discussion and comment purposes. They have not been peer-reviewed or been subject to the review by the NBER Board of Directors that accompanies official NBER publications.

(C) 2016 by Will Dobbie, Paul Goldsmith-Pinkham, Neale Mahoney, and Jae Song. All rights reserved. Short sections of text, not to exceed two paragraphs, may be quoted without explicit permission provided that full credit, including $\odot$ notice, is given to the source. 
Bad Credit, No Problem? Credit and Labor Market Consequences of Bad Credit Reports

Will Dobbie, Paul Goldsmith-Pinkham, Neale Mahoney, and Jae Song

NBER Working Paper No. 22711

October 2016

JEL No. G28,J23,J38,J71,K31,K35

\begin{abstract}
$\underline{\text { ABSTRACT }}$
Credit reports are used in nearly all consumer lending decisions and, increasingly, in hiring decisions in the labor market, but the impact of a bad credit report is largely unknown. We study the effects of credit reports on financial and labor market outcomes using a difference-indifferences research design that compares changes in outcomes over time for Chapter 13 filers, whose personal bankruptcy flags are removed from credit reports after 7 years, to changes for Chapter 7 filers, whose personal bankruptcy flags are removed from credit reports after 10 years. Using credit bureau data, we show that the removal of a Chapter 13 bankruptcy flag leads to a large increase in credit scores, and an economically significant increase in credit card balances and mortgage borrowing. We study labor market effects using administrative tax records linked to personal bankruptcy records. In sharp contrast to the credit market effects, we estimate a precise zero effect of flag removal on employment and earnings outcomes. We conclude that credit reports are important for credit market outcomes, where they are the primary source of information used to screen applicants, but are of limited consequence for labor market outcomes, where employers rely on a much broader set of screening mechanisms.
\end{abstract}

Will Dobbie

Industrial Relations Section

Princeton University

Firestone Library

Princeton, NJ 08544-2098

and NBER

wdobbie@princeton.edu

Paul Goldsmith-Pinkham

Federal Reserve Bank of New York

33 Liberty St

New York, NY 10045

paulgp@gmail.com
Neale Mahoney

Booth School of Business

University of Chicago

5807 South Woodlawn Avenue

Chicago, IL 60637

and NBER

Neale.Mahoney@chicagobooth.edu

Jae Song

Social Security Administration

Office of Disability Adjudication

and Review

5107 Leesburg Pike, Suite 1400

Falls Church, VA 22041

jae.song@ssa.gov 


\section{Introduction}

The increasing availability and richness of credit report data is one of the most significant changes to consumer financial markets in the last 25 years. In the United States, credit reports—and the associated credit scores-are used in nearly all consumer lending decisions, including both approval and pricing decisions for credit cards, private student loans, auto loans, and home mortgages. Credit reports are also widely used in non-lending decisions, such as rental decisions for apartments and hiring decisions in the labor market. ${ }^{1}$

Proponents of this trend argue that the increased use of credit reports is a key factor driving the expansion of lending to traditionally underserved segments of the population, including minority communities that have been historically shut out of formal credit markets (e.g., Staten, 2014). Critics recognize the importance of credit report data in theory, but argue that these benefits should be weighed against individuals' rights to privacy (Shorr, 1994) and the so-called right to be forgotten (Steinberg, 2014). And critics have been particularly concerned about the use of credit reports in hiring decisions in the labor market. In the years following the Great Recession, a series of prominent news articles reported on how a bad credit report can be a major impediment to finding a job. ${ }^{2}$ Talking to the New York Times, a lawyer at the National Consumer Law Center called the scenario "a bizarre, Kafkaesque experience ... Someone loses their job, so they can't pay their bills-and now they can't get a job because they couldn't pay their bills because they lost a job? It's this Catch-22 that makes no sense." This debate is currently playing out across the country, with ten states having passed laws to restrict employer credit checks since 2007, and federal legislators introducing a similar law in $2015 .^{3}$ To date, however, there is little empirical evidence determining whether the anecdotal evidence linking credit reports to employment represents a broad-based, causal phenomenon.

This paper estimates the causal effect of an improved credit report on financial and labor market outcomes. Our research design uses the sharp removal of personal bankruptcy "flags" from credit reports at statutorily determined time horizons. Nearly all households that declare bankruptcy file

\footnotetext{
${ }^{1}$ The Society of Human Resource Management (SHRM, 2010) reported that 60 percent of employers conducted background checks for some of their candidates in 2010, up from 25 percent of employers in 1998. See FRB (2007) and CFPB (2012) for additional discussion on the uses of credit reports.

${ }^{2}$ See National Public Radio (2012) and New York Times (2013). The April 10th, 2016 episode of the TV Show “Last Week Tonight with John Oliver" also reported on this issue.

${ }^{3}$ The federal bill, "The Equal Employment for All Act" (H.R. 321), aimed to "amend the Fair Credit Reporting Act to prohibit the use of consumer credit checks against prospective and current employees for the purposes of making adverse employment decisions." The bill was introduced by Senator Elizabeth Warren in August, 2015. See Clifford and Shoag (2016) for more on these policies.
} 
under either Chapter 13 or Chapter 7 of the U.S. Bankruptcy Code. ${ }^{4}$ Under the Fair Credit Reporting Act (FCRA), credit bureaus are required to remove Chapter 7 bankruptcy flags ten years after filing. In contrast, credit bureaus traditionally remove Chapter 13 flags only seven years after filing, three years before the Chapter 7 flag is removed. ${ }^{5}$

We use this variation in a difference-in-differences research design that compares outcomes for Chapter 13 filers (the "treatment" group), who have their flags removed at seven years, to Chapter 7 filers (the "control" group), who have their flags removed at ten years and are therefore unaffected at the seven-year time horizon. The identifying assumption for this difference-in-differences specification is that, in the absence of the Chapter 13 bankruptcy flag removal, outcomes for treated and control individuals would have evolved in parallel. To provide support for this "parallel trends" assumption, we show that the path of outcomes for treated and control individual are virtually identical in the pre-flag removal period.

We measure the effects of flag removal using two large administrative datasets. We examine the effects on credit market outcomes-including credit scores and measures of both credit card and mortgage borrowing - using a dataset generated from the Federal Reserve Bank of New York Equifax Consumer Credit Panel (CCP). Equifax is one of the three main credit bureaus, and their data provide us with panel information on nearly all credit products held by an individual over time. To examine the effects on labor market outcomes, we use data from individual bankruptcy filings merged to administrative tax records at the Social Security Administration (SSA). Our primary analysis sample, which focuses on prime-age adults with a bankruptcy flag removal between 2002 and 2011, covers roughly 400,000 individuals in the Equifax sample and 4.7 million individuals in the SSA sample.

We begin our analysis by examining the "first stage" effect of the bankruptcy flag removal on credit scores. Since credit scores are used in the vast majority of lending decisions, improvements in credit scores directly translate into increased credit availability, lower interest rates, or both. We show that bankruptcy flag removal leads to an immediate 10 point increase in credit scores on a preflag removal base of 596. The jump occurs precisely in the quarter of bankruptcy flag removal and

\footnotetext{
${ }^{4}$ Under Chapter 7, debtors forfeit all non-exempt assets in exchange for a discharge of eligible debts and protection from future wage garnishment. Under Chapter 13, filers propose a three- to five-year plan to repay part of their unsecured debt in exchange for a discharge of the remaining unsecured debt, protection from future wage garnishment, and protection of most assets. Nearly all unsecured debts are eligible for discharge under both chapters, including credit card debt, installment loans, medical debt, unpaid rent and utility bills, tort judgments, and business debt. See Section 3 for additional details of the bankruptcy system in the United States.

${ }^{5}$ Under FCRA, Chapter 13 flags are not mandated to be removed earlier than Chapter 7 flags, but all three national credit bureaus do so voluntarily. All three credit bureaus state that the Chapter 13 flag is removed at seven years in their documentation, and we have confirmed this independently using the Equifax credit report data described below. We have also confirmed that the Chapter 7 flag is removed at ten years, as mandated by the FRCA, using the Equifax data.
} 
declines over time. Since credit scores are based on a regression of default on observables, we can interpret the effect in terms of a change in the implied probability of default. Using this measure, we find that flag removal leads to a 3 percentage point decline in the implied default probability on a pre-flag removal base of 32 percent (roughly a 10 percent decrease in riskiness).

We next show that flag removal has a statistically and economically significant effect on credit card borrowing. The effect appears immediately and grows linearly over time. At a three-year horizon, we estimate that flag removal increases credit limits by $\$ 1,510$ on a pre-flag removal mean of $\$ 3,027$ and raises credit card balances by $\$ 800$ on a pre-flag removal mean of $\$ 1,911$. The ratio of the increase in balances to the increase in credit limits is 53 percent, although we caution that the effect should not be interpreted as a pure MPC out of liquidity because some of the effect may operate through lower interest rates, which we do not observe. Credit limits are also determined by credit card balances, so this ratio may reflect some reverse causality.

We similarly find a large effect on mortgage borrowing. In contrast to the credit card results, the effect is concentrated in the first year. One year after flag removal, the fraction of individuals with a mortgage increases by 1.9 percentage points on a pre-flag removal base of 41.3 percent (a 4.6 percent increase). In heterogeneity analysis, we show that the effect is concentrated among individuals who had their flags removed during the 2008 to 2011 period, with no effect of flag removal in prior years. The results are consistent with widespread mortgage access in the run-up to the Financial Crisis, with subprime mortgage lenders providing loans to consumers with blemished credit reports, and substantial pent-up demand in the post-crisis period due to significantly tighter lending standards in the subprime mortgage market.

In stark contrast to our credit market results, we estimate a zero effect of flag removal on labor market outcomes with 95 percent confidence intervals that allow us to rule out economically significantly increases. At three years after flag removal, the 95 percent confidence interval allows us to rule out an increase in employment of greater than 0.4 percentage points on a pre-flag removal base of 85.0 percent and an increase in earnings of greater than 0.8 percent. We estimate similarly precise zero effects on self-employment and self-employment earnings, indicating that these results are not masking reallocation between different types of work.

In principle, the zero result we estimate may stem from countervailing effects on labor supply and labor demand. In particular, since flag removal increases access to credit, it might reduce labor supply through a credit smoothing effect, thereby offsetting any increase in employers' labor demand. 
We investigate this theory by exploiting heterogeneity across individuals in the effect of flag removal on credit access. We show that there is a zero effect across individuals with different pre-flag removal credit card utilization, including individuals with relatively low credit card utilization. Since individuals with low pre-flag removal utilization were not credit constrained, this analysis isolates a group of individuals where changes in employers' labor demand should be the dominant force. And we show that the effect is zero across individuals with different size increases in credit limits, including individuals with very small changes, where labor demand should also be dominant. Given the results from this heterogeneity analysis, we interpret the zero estimates as indicating no average effect of flag removal on labor demand.

Because of the contrary anecdotal evidence linking credit reports and employment, we conduct a broad set of heterogeneity and sensitivity analyses of these labor market results. (i) We estimate precise and economically small effects for different demographic groups, including for minorities where there have been particular concern about the employment consequences of derogatory credit reports. ${ }^{6}$ (ii) We find economically small effects across the business cycle, including just after the financial crisis when labor markets were slack. (iii) We find no effect on employment dynamics, including the "no job" to "any job" transition, where you might expect to see the largest employment response. (iv) We also find no evidence that employment shifts towards industries like finance, which more frequently use credit checks to screen applicants (SHRM, 2010). (v) Finally, we find no employment effects in states that did not restrict employer credit checks (or in states that did restrict credit checks, for that matter).

In interpreting the null effects on labor market outcomes, a natural question is whether employers consider a seven-year-old bankruptcy filing to be important relative to other derogatory items that could appear on a job applicant's credit report. We discuss survey evidence that shows that the bankruptcy flags are one of the key variables that employers consider and that a seven-year time horizon after filing is within the look-back period that many employers typically scrutinize.

We conclude that credit reports are important for credit market outcomes, where they are the primary source of information used to screen applicants, but are of limited consequence for labor market outcomes, where employers rely on a much broader set of screening mechanisms. Our results also suggest that recent political attempts to limit the use of credit reports by employers are unlikely

\footnotetext{
${ }^{6}$ For instance, the NAACP and National Council of La Raza, among many other organizations, wrote a letter cosponsoring the "The Equal Employment for All Act" (H.R. 321), which aimed "to prohibit employers from using credit checks as part of their hiring and promotion decisions for most positions," because they viewed credit checks as discriminatory, among other reasons. The bill was introduced in January 2011, but did not pass.
} 
to affect labor market outcomes, either positively or negatively.

Our paper is related to a number of recent working papers that examine the effects of credit reports on credit and labor market outcomes conducted in parallel to our study. ${ }^{7}$ Gross, Notowidigdo and Wang (2016) use credit bureau data and an event-study design to estimate the effect of bankruptcy flag removal on credit card limits and credit card balances. Their implied MPC estimate is similar to ours, but their main objective is to estimate heterogeneity in the MPC over the business cycle. Herkenhoff, Phillips and Cohen-Cole (2016) use administrative employment data from the Census and an eventstudy design to estimate the employment consequences of bankruptcy flag removal. Like us, they find zero or very small effects of flag removal on self-employment and formal sector employment and earnings. They do, however, find that flag removal increases churn in and out of employment, and use these results to calibrate a directed search model of labor market transitions. Clifford and Shoag (2016) use employment and credit score data aggregated to the Census tract level and a stateyear difference-in-differences research design to study the employment effects of recent state-level restrictions on employer credit checks. They find that restrictions have a zero average effect among Census tracts with average credit scores below 650. However, in subsample analysis, the authors find positive effects for census tracks with the lowest average credit scores. These estimates contrast with our results that show no employment effects across the credit score distribution.

Finally, outside of the United States, our research is related to a paper by Bos, Breza and Liberman (2016) that studies a policy that reduced the time that information on default was listed on credit reports in Sweden. Their analysis focuses on individuals who defaulted on a pawnshop loan, who make up around two percent of the Swedish population (Bos, Carter and Skiba, 2012). They find that the removal of default information leads to a 3 percentage point increase in employment. By comparison, we focus on individuals who have filed for bankruptcy, which make up approximately 15 percent of the United States population according to our calculations using the CCP data, and we rule out employment effects greater than 0.4 percentage points with 95 percent confidence. We are also unable to find any subgroup where employment effects are larger than 3 percentage points, suggesting that the labor market effects of bad credit reports are much smaller in the United States than Sweden, at least for the respective populations examined in these studies. ${ }^{8}$

\footnotetext{
${ }^{7}$ The recent literature builds on work by Musto (2004), who studies the impact of bankruptcy flag removal on credit scores and credit card borrowing using an event-study design. Musto (2004) finds that flag removal has a sharp short run effect on credit scores and credit card borrowing, but has adverse longer run consequences. In contrast, our difference-in-differences research design, which is better suited to study longer run effects, does not show such strong evidence of adverse longer run outcomes.

${ }^{8}$ Bos, Breza and Liberman (2016) estimate that the removal of default information increases credit by about $\$ 105$ over
} 
The rest of our paper proceeds as follows. Section 2 presents background on credit reporting and describes our data. In Section 3, we presents our research design. Section 4 presents our results for the credit market and labor market outcomes. Section 5 concludes.

\section{Background and Data}

\subsection{Credit Reporting}

The history of credit reporting in the United States can be traced back to the nineteenth century, when third parties sold lists of deadbeat borrowers to local merchants. The credit reporting industry grew throughout the twentieth century, but remained highly fragmented, with 2,250 local and regional firms as of 1970. During the 1970s and 1980s, the rapid growth in credit card lending fueled an expansion and consolidation of the credit bureau industry. Today, there are three national credit reporting agencies-Equifax, TransUnion, and Experian—that provide most credit reports. See CFPB (2012) for more on the history of the credit reporting system.

Along with basic information on name, address, and Social Security number (SSN), consumer credit reports provide four main categories of information:

(i) The tradeline segment provides information on contract characteristics, utilization, and delinquency or default at the product level. For instance, for an individual credit card, the tradeline data include information on the credit limit, account balance, and whether the consumer is in delinquency or default. The tradeline data are provided to the credit bureaus by the lenders, which are typically large national banks.

(ii) The public records segment includes information on bankruptcies and tax liens. Non-financially relevant public information, such as marriage records, are not included in the credit report. These data are obtained from the Public Access to Court Electronic Records (PACER) system and government offices.

(iii) The collections segment provides information on debts under collection, and is reported to the credit bureaus by third-party collection agencies.

(iv) The inquiries segment provides information on consumer-initiated credit requests, known as

their time horizon, with an implied annual effect of $\$ 236$. We find that the removal of a personal bankruptcy flag increases credit card borrowing by $\$ 799$ after three years, implying an annualized effect of $\$ 267$ dollars. We also find increases in mortgage borrowing of 1.0 to 1.8 percent. These results suggest that our (null) labor market findings are not the result of a weak "first stage." 
"hard" inquiries. "Soft" inquiries, which result, for example, from a bank-initiated pre-screening, are typically not reported.

The Fair Credit Reporting Act (1970) limits the amount of time that information can be maintained on credit reports. Chapter 7 bankruptcies may be listed for ten years after the order for relief or date of adjudication. Conversely, information on Chapter 13 bankruptcies is traditionally removed after a period of only seven years. ${ }^{9}$ The FCRA also stipulates that information on late payments, delinquencies, and collection items be removed after seven years.

Requestors of credit bureau information do not necessarily receive the full set of credit bureau data. Potential employers, for instance, usually receive modified credit reports that do not contain date of birth or credit scores. Lenders, on the other hand, usually receive at least one consumer credit score, in addition to all of the standard credit report information. These credit scores are sometimes developed by third parties, such as the Fair Isaac Corporation (FICO), and sometimes developed by the credit bureaus themselves (e.g., the VantageScore). There are also dozens of different types of credit scores, each based on different outcome variables and used for different types of lending decisions. The most commonly used credit scores aim to predict the probability that a consumer will become 90+ days delinquent on a new loan within the next 24 months. See CFPB (2012) for more background on the U.S. credit reporting system.

\subsection{Data Sources and Sample Construction}

We use two separate datasets to estimate the impact of removing a Chapter 13 bankruptcy flag on credit scores, financial outcomes, and formal sector employment and earnings. The first dataset uses information from the Federal Reserve Bank of New York's Equifax Consumer Credit Panel (CCP). The second dataset uses information from individual bankruptcy filings merged to administrative tax records at the Social Security Administration (SSA).

The first dataset used in our analysis is constructed using records from the CCP, a representative five percent random sample of all individuals in the U.S. with credit files. ${ }^{10}$ Like other credit report data, the CCP data are derived from public records, collections agencies, and trade lines data from

\footnotetext{
${ }^{9}$ Under FCRA, Chapter 13 flags are not mandated to be removed earlier than Chapter 7 flags, but all three national credit bureaus do so voluntarily. All three credit bureaus state that the Chapter 13 flag is removed at seven years in their documentation, and we have confirmed this independently using the Experian credit report data described below. We have also confirmed that the Chapter 7 flag is removed at ten years, as mandated by the FRCA, using the Experian data.

${ }^{10}$ The CCP data is a representative sample of all individuals with a credit file, but does not include the roughly 11 percent of the U.S. population without credit files. As a result, the CCP data will be more representative for high income individuals than for low income individuals.
} 
lending institutions. The data include a comprehensive set of consumer credit outcomes, including information on credit scores, unsecured credit lines, auto loans, and mortgages. The data also include year of birth and geographic location at the ZIP-code level. No other demographic information is available at the individual level. Importantly, the data also include information on the bankruptcy chapter, the bankruptcy outcome, and the quarter that a bankruptcy flag is both placed and removed from the credit file. ${ }^{11}$ The CCP data are available quarterly from 1999 to 2015. See Avery et al. (2003) and Lee and der Klaauw (2010) for additional details.

We make three sample restrictions to the CCP data. First, we restrict the sample to individuals who filed for bankruptcy protection between 1995 and 2004. This restriction allows us to observe credit outcomes both before and after the flag removal. Second, we restrict our sample to individuals who were between 23 and 47 years old at filing —and therefore 30 and 54 years old at seven years after filling - to focus on working-age adults. Third, we restrict the sample to individuals who completed the bankruptcy process, receiving what is known as a discharge. ${ }^{12}$

The second dataset constructed for this study consists of individual bankruptcy filings merged to administrative tax records at the SSA. Bankruptcy records are available from 1992 to 2009 for the 81 (out of 94) federal bankruptcy courts that allow full electronic access to their dockets. ${ }^{13}$ We matched the individual-level bankruptcy records to administrative tax records from the SSA using last name and the last four digits of the filer's SSN. We were able to successfully match over 90 percent of the bankruptcy records, with nearly all of the unmatched records resulting from a shared name and last four digits of the SSN in the SSA data. ${ }^{14}$ The SSA data include information on all formal sector earnings and employment from annual W-2s, and self-employment earnings from annual 1040s at the IRS. Individuals with no W-2 or self-employment earnings in any particular year are assumed to have had no formal sector earnings in that year. Individuals with zero earnings are included in all regressions throughout the paper. The SSA data are available annually from 1978 to 2014.

\footnotetext{
${ }^{11}$ We are unable to observe filing quarter for individuals filing before the first quarter of 1991. For these individuals, we infer the filing quarter based on when their bankruptcy flag is removed from their credit report. Specifically, we impute the filing quarter as being seven years before the quarter of flag removal for Chapter 13 filers, and ten years before the quarter of flag removal for Chapter 7 filers. In results available upon request, we find that the number of Chapter 7 and Chapter 13 filings in the CCP data closely track the number of filings observed in administrative bankruptcy records.

${ }^{12}$ Chapter 13 filers who do not receive a discharge have their flags removed after ten years and therefore cannot be used in our research design.

${ }^{13}$ We thank Tal Gross, Matthew Notowidigdo, and Jialan Wang for providing the bankruptcy data used in this analysis. See Gross, Notowidigdo and Wang (2014) for additional details on the PACER bankruptcy data.

${ }^{14}$ The SSA data include every individual who has ever acquired a SSN, including those who are institutionalized. However, illegal immigrants without a valid SSN are not included in the SSA data. The SSA data also does not include information on informal earnings or employment.
} 
Following our sample restrictions for the CCP data, we restrict the matched bankruptcy-SSA data to individuals who filed for bankruptcy protection between 1995 and 2004, were between 30 and 54 years old seven years after filing, and successfully completed the bankruptcy process. All dollar amounts in the SSA dataset are adjusted to year 2013 dollars using the CPI-U.

Table 1 provides summary statistics on the CCP and SSA data, for Chapter 7 and Chapter 13 filers separately, and for the combined sample.

\section{Research Design}

We estimate the impact of bankruptcy flag removal using a difference-in-differences research design that compares the outcomes of Chapter 13 filers (the "treatment" group), who have their flags removed at seven years, to the outcomes of Chapter 7 filers (the "control" group), who have their flags removed at ten years and are therefore unaffected at the seven-year time horizon.

Our sample of 1995 to 2004 bankruptcy filings occurred before the 2005 bankruptcy reform (i.e., the Bankruptcy Abuse Prevention and Consumer Protection Act of 2005, or BAPCPA). Below we provide a brief overview of Chapter 13 and Chapter 7 bankruptcy under the pre-reform bankruptcy code; see Dobbie and Song (2015), Dobbie, Goldsmith-Pinkham and Yang (2015) and Mahoney (2015) for a more in-depth treatment. Under Chapter 7, bankruptcy filers forfeit all non-exempt assets in exchange for a discharge of eligible debts and protection from future wage garnishment. Nearly all unsecured debts are eligible for discharge under Chapter 7, including credit card debt, installment loans, medical debt, unpaid rent and utility bills, tort judgments, and business debt. Student loans, child support obligations, and debts incurred by fraud cannot be discharged under Chapter 7, and secured debts such as mortgages, home equity loans, and automobile loans can only be discharged if filers give up the collateral.

Under Chapter 13 bankruptcy, filers propose a three- to five-year plan to partially repay their unsecured debt in exchange for a discharge of the remaining unsecured debt, a hold on debt collection, and the retention of most assets. Chapter 13 requires filers to use all of their disposable income, defined as their predicted income less predicted expenses, to repay creditors. Creditors must receive at least as much as they would have received if the filer's assets were liquidated under Chapter 7,

a requirement known as the "best interest of creditors" test. Chapter 13 filers are also required to fully repay priority claims, such as child support and alimony, unless the claimant agrees to a reduced payment. If a filer wants to keep any collateral securing a claim, he or she must keep up to date on all 
current payments and include any arrears in the repayment plan. The filer can also choose to give up the collateral and discharge the remaining debt. ${ }^{15}$

In any given year, approximately 70 percent of filers choose Chapter 7 of the bankruptcy code, with the remaining 30 percent choosing Chapter 13 (White, 2007). One reason why individuals choose Chapter 13 is that it allows filers to avoid a home foreclosure or the repossession of a car by including any arrears in the repayment plan, with the original debt contract reinstated on completion of the Chapter 13 repayment plan. Thus, perhaps not surprisingly, the biggest difference between Chapter 13 and Chapter 7 filers in Table 1 is the fraction of individuals with a mortgage (41.6 percent for Chapter 13 filers versus 32.6 percent for Chapter 7 filers). However, there is also evidence that filers are steered into Chapter 13 by lawyers who earn larger payments from Chapter 13 filings, generating variation in filing chapter that is more likely to be uncorrelated with the individual's financial circumstances (Braucher, Cohen and Lawless, 2012). As we discuss below, our research design does not rely on the random assignment of filing chapter. Rather, the key identifying assumption for our differencein-differences specification is that the differences in outcomes for Chapter 13 versus Chapter 7 filers would have evolved in parallel in the absence of the Chapter 13 bankruptcy flag removal.

We conduct our analysis using individual-level data collapsed to a more aggregate level to speed up the regression analysis. In the CCP data, we collapse by the full interaction of chapter of filing, cohort of filing, time period, state of residence, and five-year age bins. In the SSA data, we also observe race (defined as white or non-white) and gender, so we additionally collapse on these dimensions. ${ }^{16}$ In our regression specifications, we weight each of the resulting cells by the number of underlying individual observations so that our estimates are representative of the underlying individual-level data. As we discuss below, collapsing the data does not affect the statistical inference because we cluster our standard errors above the level of aggregation.

The precise regression specifications will naturally differ based on whether we use the quarterly CCP data or the annual SSA data. Consider first the quarterly CCP data. Let $i$ index filing groups, defined by the full interaction of chapter of filing, cohort of filling, state of residence, and 5-year age bin. Let $s$ index calendar-time, defined at the year-quarter level. Let $t$ indicate event-time, defined as quarters relative to the seven-year horizon when Chapter 13 bankruptcy flags removed. We define $t$

\footnotetext{
${ }^{15}$ In our main results, we include all Chapter 13 filers, regardless of repayment plan length. In results available upon request, we find identical results restricting the sample to filers with either 3-year or 5-year repayment plans.

${ }^{16}$ In the CCP data, cohort and time period are defined at the year-quarter level and state of residence is defined using the state of residence six years after filing. In the SSA data, which is only available at the annual level, we define cohorts and time periods at the year level and state of residence is defined at the time of filing. We have examined the effect of flag removal on state of residence and find no effect. These results are available upon request.
} 
using this seven-year horizon for both Chapter 13 and Chapter 7 filers even though Chapter 7 filers have their flags removed at ten years. The collapsed data is at the $i \times t$ level.

For a given outcome, $y_{i t}$, our difference-in-differences regression specification takes the form:

$$
y_{i t}=\alpha_{i}+\alpha_{t}+\alpha_{s(i, t)}+\left[\sum_{t \neq-1} \beta_{t} \cdot \mathbf{1}(\text { Chapter 13) }]+\varepsilon_{i t}\right.
$$

where $\alpha_{i}$ are filing group fixed effects, $\alpha_{t}$ are event-time fixed effects, $\alpha_{s(i, t)}$ are calendar-time fixed effects, $\mathbf{1}$ (Chapter 13) is an indicator for filing under Chapter 13, and $\beta_{t}$ are coefficients on Chapter 13 that vary non-parametrically by event time. We omit the period prior to flag removal, $\beta_{t=-1}$, so that the other $\beta_{t}$ 's can be interpreted relative to this pre-removal baseline period. We also drop the base effect for the quarter prior to flag removal, $\alpha_{t=-1}$, as it is not separately identified from the other fixed effects in the specification. When we estimate this model using the annual SSA data, the eventtime and calendar-time fixed effects are defined at the annual level, but otherwise the specification is unchanged. ${ }^{17}$

In this specification, the $\beta_{t}$ coefficients for $t>0$ can be interpreted as the differential change in $y_{i t}$ for Chapter 13 filers relative to Chapter 7 filers following the Chapter 13 bankruptcy flag removal. The identifying assumption is parallel trends: conditional on our controls, $y_{i t}$ would have followed a similar evolution for both groups of filers in the absence of the Chapter 13 flag removal. This identifying assumption would be violated if Chapter 13 and Chapter 7 filers have different trends in $t$. For example, our identifying assumption would be violated if Chapter 13 filers recover either faster or slower from a bankruptcy filing compared to Chapter 7 filers.

Our main approach to assess the validity of this assumption is to examine outcomes for the treated and control filers in the pre-flag removal period. As discussed below, our plots of the raw data and the non-parametric specifications both show that outcomes for Chapter 13 and Chapter 7 filers move in close parallel during the pre-flag removal period for most outcomes. These results give us confidence that our control group is valid and that it provides us with an accurate counterfactual for what would have happened to the treatment group in the absence of flag removal.

To gauge the magnitude and statistical significance of the results in the quarterly CCP data, we

\footnotetext{
${ }^{17}$ In this specification, we are only able to control for year, rather than year-quarter, calendar-time fixed effects due to the collinearity of the event-time and calendar-time fixed effects. In our table results, we are able to control for year-quarter calendar-time fixed effects since our event-time estimates are simplified into three coefficients. When we estimate this specification using the annual SSA data, we are analogously only able to control for two-year calendar-time fixed effects when we include all event-time fixed effects, but are able to control for single-year calendar-time fixed effects in the tables, where our event-time estimates are again simplified into three coefficients.
} 
also estimate a specification that pools the effect across sets of consecutive quarters in the post-flag removal period. Specifically, we estimate a specification where we replace the quarter-specific coefficients in the post-flag removal period with three post-flag removal coefficients: $\beta_{1}$, which pools over quarters $t \in[0,4), \beta_{2}$, which pools over quarters $t \in[4,8)$, and $\beta_{3}$, which pools over quarters $t \in[8,12)$. Other than these pooled coefficients, the specification is identical to that in Equation (1). Since our SSA data is already annual, we do not need to run a different pooled specification in these data.

In all specifications, we cluster our standard errors at the full interaction of the chapter of filing, cohort of filing, and state of residence in the pre-flag removal period. This approach is more conservative than clustering at the individual level, and, for example, allows individuals who filed for Chapter 13 in California in 1998 to face correlated credit and labor market shocks when their bankruptcy flags are removed in 2005.

\section{Results}

In this section, we examine the effects of the Chapter 13 flag removal using our difference-in-differences research design. We first analyze the effects of flag removal on credit scores, before turning to its effects on credit card borrowing, mortgage borrowing, and labor market outcomes.

\subsection{Credit Scores}

We begin with a descriptive analysis of how credit scores evolve for Chapter 13 and Chapter 7 bankruptcy filers just before and just after flag removal. Since credit scores are used in the vast majority of lending decisions, improvements in credit scores should directly translate into increased credit availability, lower interest rates, or both (FRB, 2007).

Figure 1 provides some background on credit scores. The credit score we observe-the Equifax Risk Score 3.0-is the output of "a general-purpose risk model that predicts the likelihood of a consumer becoming seriously delinquent (i.e., 90+ days past due) within 24 months of scoring."18 The observed credit score is constructed as an odds-scale measure of risk, with the odds of going seriously delinquent doubling for every 33 point decline in the credit score measure. The exact credit score formula is a proprietary trade secret. ${ }^{19}$

Panel A of Figure 1 plots the distribution of credit scores for a representative, unrestricted sample

\footnotetext{
${ }^{18}$ See http: / / www . equifax.com/biz/debt_recovery_pdfs/EFS-670-ADV20ERS203.0.pdf

${ }^{19}$ The FICO credit score is constructed in a similar fashion. See CFPB (2011) for more information.
} 
of the CCP data and for our analysis sample of bankruptcy filers. In the representative sample, credit scores have a mean of 686 and an interquartile range of 607 to 778 . Our analysis sample is drawn from the lower part of the distribution, and has a mean of 600 and an interquartile range of 553 to 658. Panel B shows the relationship between observed credit scores and serious delinquency (90+ days past due). ${ }^{20}$ The mean credit score of 600 in our analysis sample corresponds to a 30.2 percent probability of default in the following two years. To facilitate the economic interpretation of the effect on credit scores, we construct an alternative outcome measure called the implied probability of default, which is simply the credit score mapped into a probability of default using the relationship shown in Panel B of Figure 1.

Figure 2 plots average credit scores and the implied probability of default for Chapter 13 filers (the "treatment" group) and Chapter 7 filers (the "control" group) for each quarter relative to Chapter 13 flag removal. The vertical lines show the quarter of Chapter 13 flag removal and the quarter of Chapter 7 flag removal, which occurs three years later. Outcomes are normalized to the average value of the outcome for Chapter 13 filers in the quarter prior to flag removal.

Panel A shows that prior to flag removal, credit scores for both groups trend upwards together, confirming the parallel trends identifying assumption. In the quarter of Chapter 13 flag removal, there is a clear jump of approximately ten points for the credit scores of Chapter 13 filers. After flag removal, average credit scores for Chapter 7 filers continue their upward trend, although at a slightly lower rate, and average credit scores for Chapter 13 filers decline slightly in absolute value and more strongly relative to the Chapter 7 control group. ${ }^{21}$ At three years post-removal, the credit scores of Chapter 13 filers remain approximately 3 points above those of Chapter 7 filers.

Panel B shows trends for the implied probability of default. The pre-flag removal trend is downward because of the inverse relationship between credit scores and default probabilities. In the quarter of Chapter 13 flag removal, the implied probability of default drops by approximately 3 percentage points on a base on 32 percent. Post-flag removal, there is some reversion, and at three years post-flag

\footnotetext{
${ }^{20}$ To avoid complications from over-time variation in default rates, the figure focuses on credit scores in the first quarter of 2005 and default rates in the first quarter of 2007, which is a time period near the midpoint of our sample.

${ }^{21}$ This decrease in slope is due to a change in the rate of removal of flags for delinquencies and collections items, which are also removed after seven years for both Chapter 13 and Chapter 7 filers. Accounting for the change in slope is a key advantage of our difference-in-differences research design relative to an event study design without a control group of Chapter 7 filers. The change in slope occurs for the following reason: Since prior to filing for bankruptcy individuals are receiving flags for delinquencies and collections items, prior to bankruptcy flag removal the upward slope in credit scores partially reflects the removal of these flags. However, after bankruptcy filing, individuals are no longer receiving new delinquencies and collections flags, so after the bankruptcy flag removal there are no more removals of delinquencies and collections flags, and hence the slope of credit scores is flatter. See Dobbie, Goldsmith-Pinkham and Yang (2015) for an analysis of pre- and post-filing trends in credit scores, delinquencies, collection items, and other credit market outcomes, and see Dobbie and Song (2015) for an analogous analysis on pre- and post-filing trends in labor market outcomes.
} 
removal, there is only a 0.5 percentage point difference between Chapter 13 and Chapter 7 filers in the implied probability of default.

Table 2 shows results from our parametric difference-in-differences regressions that pool the effect across the first, second, and third years after flag removal. In these specifications, we omit the quarter before flag removal, so that the effects can be interpreted relative to the pre-removal period. We also control for chapter-by-cohort-by-age-by-state and calendar-year fixed effects and cluster standard errors at the chapter-by-cohort-by-state level. The point estimates indicate that credit scores increase by $9.8,6.3$, and 3.2 points, and that the implied probability of default declines by $2.6,1.6$, and 0.6 percentage points in the first, second, and third years after flag removal, respectively.

Appendix Figure A1 plots the coefficient of interest from the non-parametric difference-in-differences specification shown in Equation (1) with credit scores and the implied probability of default as the dependent variables. The plots show no systematic relationship between flag removal and these outcome variables in the pre-removal quarters, providing support for our parallel trends identifying assumption, and more generally corroborating our results on the timing and size of the effect.

In the Appendix, we examine heterogeneity by predicted pre-flag removal credit score. ${ }^{22}$ In particular, Appendix Figure A2 plots average credit scores for Chapter 13 filers and Chapter 7 filers for different quartiles of the predicted pre-flag removal credit score, and Appendix Table A1 shows estimates from our corresponding non-parametric specification that pools effects by year. The degree of reversion to pre-removal credit scores is decreasing sharply in predicted credit score. For the lowest predicted credit score quartile, average credit scores for the treated Chapter 13 filers drop below the average credit scores for the Chapter 7 control group two to three years post-removal. Conversely, for the highest predicted credit score quartile, average credit scores for the treated Chapter 13 filers drop very little in absolute or relative terms. While interesting, these results do not have a clear interpretation, as changes in credit scores across groups reflect both heterogeneity in economic outcomes, and functional form and other modeling assumptions that go into the credit score formula. ${ }^{23}$

\footnotetext{
${ }^{22}$ In our setting, segmenting the data by actual pre-flag removal credit score is problematic, because it is difficult to separate changes in credit scores due to mean reversion (i.e., low credit scores rising and high credit scores falling) and due to heterogeneity in the causal effect of flag removals. For example, mean reversion occurs in our setting when an individual accidentally misses a payment, has their score lowered, and then catches up on the overdue payment, and has their score immediately recover. In this scenario, we would mistakenly attribute the rise in credit scores to a larger treatment effect. To overcome this issue, we split the data on stable characteristics that are predictive of credit scores, but do not suffer from mean reversion. Specifically, we segment the data by first running a linear regression of pre-flag removal credit score on fully interacted fixed effects for age group and state of residence, and then bin the data based on the predicted credit scores from this regression.

${ }^{23}$ For completeness, Appendix Figure A3 and Appendix Table A1 show the analogous plots and parameter estimates with the implied probability of default as the dependent variable. Other than the inverse relationship, the patterns are
} 


\subsection{Credit Card Debt}

We examine two summary measures for credit card borrowing: (i) credit limits aggregated across all cards, and (ii) total balances aggregated across all cards. Balances reported in the credit bureau data reflect interest bearing debt, which the consumer pays interest on, and transaction volume, which is fully repaid at the end of the billing cycle and therefore does not accrue interest. However, Agarwal et al. (2015) show that for consumers with credit scores in the bottom quartile of the distribution, which is representative of the sample analyzed in this paper, more than 90 percent of balances is of the interest bearing variety, suggesting that interpreting balances as borrowing is a reasonable approximation.

Figure 3 shows average credit limits and balances for Chapter 13 and Chapter 7 filers for each quarter relative to the quarter of Chapter 13 flag removal. Table 3 shows estimates from the corresponding differences-in-differences regressions that pool the effect across the first, second, and third years after flag removal. Appendix Figure A4 plots of the coefficients of interest from the nonparametric specification shown in Equation (1).

There is an economically and statistically significant impact of flag removal on both credit card limits and balances that grows fairly linearly over time. The regression estimates in Table 3 show that flag removal increases credit limits by an average of $\$ 503$ per year. In particular, at three years after flag removal, credit limits have increased by $\$ 1,510$ on a pre-flag removal mean of $\$ 3,027$, or 50 percent. Credit card balances increase by an average of $\$ 267$ per year. At three years after flag removal, balances have increased by $\$ 800$ on a pre-flag removal mean of $\$ 1,911$, or 42 percent. Consistent with the credit score results, both figures show no pre-trend in credit card limits or balances.

It is inappropriate to interpret the ratio of the increase in balances to the increase in credit limits as a pure marginal propensity to consume out of liquidity (MPC)—such as that estimated in Gross and Souleles (2002) or Agarwal et al. (2015)—for a number of reasons. First, bankruptcy flag removal likely leads to a reduction in interest rates, and thus the increase in balances reflects both liquidity and price effects. Second, balances probably include a small amount of transaction volume that does not accrue interest, and debatably should not be considered borrowing. Third, there may be some reverse causality if higher credit limits raise balances, but then higher balances have a feedback effect on credit limits. These issues notwithstanding, taking the ratio of the increase in credit card balances to the increase in credit card limits results in a value of 53 percent at the three year horizon, relative qualitatively very similar. 
to a pre-flag removal utilization rate of 63 percent. These values are large, but almost identical to the the MPC out of liquidity estimated in Agarwal et al. (2015) for the bottom quartile of the credit score distribution.

In the Appendix, we examine heterogeneity in these effects by predicted pre-flag removal credit score, following the procedure outlined in the credit score heterogeneity analysis. Appendix Figures A5 and A7 show trends plots of the effects on credit limits and balances, and Appendix Table A1 shows the parameter estimates. The effect on credit limits and balances are increasing in pre-flag removal credit score. The ratio of the increase in balances to credit limits declines modestly in predicted preflag removal credit score, from 67 percent in the bottom quartile to 56 percent at the top quartile, based on the effects at three years after flag removal. ${ }^{24}$

\subsection{Mortgage Debt}

We examine two measures of mortgage borrowing: (i) an indicator for whether the individual has at least one mortgage, and (ii) the natural logarithm of aggregate mortgage balances plus one. We use the logarithm of aggregate mortgage balances, rather than the unadjusted level, because the distribution of mortgage balances is highly right-skewed. We add one so that we can keep observations with no mortgage balances, and hence capture both extensive and intensive margin changes in mortgage borrowing.

Figure 4 shows the averages values of these outcomes for Chapter 13 and Chapter 7 filers in each quarter relative to the quarter of Chapter 13 flag removal. Table 4 shows estimates from the corresponding differences-in-differences regressions that pool the effect across the first, second, and third years after flag removal. Appendix Figure A8 plots of the coefficients of interest from the nonparametric specification shown in Equation (1).

There is an economically and statistically significant effect of flag removal on both the probability of having at least one mortgage and the aggregate measure of mortgage debt. The effects occur almost immediately after the Chapter 13 flag removal, but fade over the next three years. The regression estimates in Table 4 show that in the first year after flag removal, the fraction of individuals with a mortgage increases by 1.9 percentage points on a pre-flag removal base of 41.3 percent, or 4.6 percent. Aggregate mortgage balances (plus one) increase by 21 log points in the first year. For the standard

\footnotetext{
${ }^{24}$ In Appendix Figure A6, we examine the responsiveness of credit card limits and balances to changes in the implied probability of default. We find that an immediate one percentage point decrease in the implied probability of default increases credit card limits by approximately 300 dollars two years later. In Panel B, we find that a similar decrease in the implied probability of default increases balances by around 100 dollars two years later.
} 
reason, this estimate should be interpreted as the average proportional increase in mortgage balances, not the proportional increase in the average mortgage balance. The pre-trends, shown in Appendix Figure A8, are zero on average across the pre-flag removal period. They exhibit a small upward trend in the year before Chapter 13 flag removal, but this increase is small economically and small relative to the increases following flag removal.

In the Appendix, we examine heterogeneity in these effects by predicted pre-flag removal credit score, again following the procedure outlined in the credit score heterogeneity analysis. Appendix Figure A9 shows trends for the mortgage indicator, and Appendix Table A1 shows the corresponding parameter estimates. The effect of a flag removal on the probability of having a mortgage is small for the bottom quartile of the predicted pre-flag removal credit score distribution, but approximately the same for the top three quartiles of the distribution. The pre-trends for the bottom quartile also show that there is an increase in mortgage holdings in the quarter before flag removal, suggesting that the effect of flag removal is slightly underestimated for this subsample.

In both the pooled and subsample results, there is also an apparent reversal in the mortgage outcomes, with values for the Chapter 13 filers falling below those for Chapter 7 filers approximately three years after flag removal. In Appendix Figure A10, we further investigate this apparent reversal, focusing on the extensive margin of having any mortgage. Panel A shows the net flow into having a mortgage. Positive net flow is the result of a new mortgage origination, and a negative net flow is the result of consumers paying off their mortgage, selling their home, or losing their home in foreclosure. The figure shows a nearly 2 percentage point increase in the net flow into mortgages in the quarter of flag removal, underscoring the sharp on-impact effect of the treatment. Consistent with the reversal in mortgage outcomes, however, Chapter 13 filers have lower net flows in the years following the flag removal.

In Panels B and C, we explore this issue further by estimating effects before and after the start of the 2008 Financial Crisis. The results are striking. There is a large, almost 3 percentage point on-impact effect of flag removal on net mortgage flows during the 2008 to 2011 period. In the pre-crisis period, however, there is no on-impact effect of flag removal on net mortgage flows, and a decline in net flows for Chapter 13 relative to Chapter 7 following flag removal. This decline in net flows for Chapter 13 after the flag removal indicates that our research design performs poorly at longer time horizons for mortgage outcomes, particularly during the pre-crisis period. Since homeownership is an important determinant of the choice between a Chapter 13 versus Chapter 7 filing, it is perhaps unsurprising 
that our research design performs relatively worse for this outcome variable. We therefore prefer to focus on the on-impact mortgage results that are less likely to be affected by this issue.

For these on-impact estimates, our results suggest an economically large effect of flag removal on mortgage originations and mortgage balances, particularly following the 2008 Financial Crisis. These results are consistent with widespread mortgage access in the run-up to the Financial Crisis, with the subprime mortgage market providing loans to consumers with blemished credit reports, and substantial pent-up demand during the post-crisis period, with tighter lending standards in the subprime market. The timing and size of the effect suggests that consumers are aware of the date of flag removal or apply for a mortgage on a frequent enough basis to generate a rapid response. The size of the effect also underscores the importance of credit scores and bankruptcy flags in this market, and is potentially surprising given the role of other factors like down payments and income-based requirements, which are also used to screen mortgage applicants.

\subsection{Labor Market Outcomes}

Our analysis of labor market outcomes follows the above analysis of financial outcomes. On the extensive margin, we examine the effects of flag removal on (i) formal sector employment, (ii) selfemployment, and (iii) the combination of either formal sector employment or self-employment. We also examine effects on (iv) formal sector wage earnings, (v) self-employment earnings, and (vi) total earnings from both formal sector employment and self-employment. We use the natural logarithm of each earnings measure, as the distributions of earnings are right-skewed. We again add one to each of the earnings measures so that we can keep observations with no reported earnings; prior to flag removal, approximately 18.0 percent of Chapter 13 filers have no formal sector earnings, 93.3 percent have no reported self-employment earnings, and 14.9 percent have no earnings of either type.

Figure 5 shows averages of these outcomes for Chapter 13 and Chapter 7 filers for each quarter relative to the quarter of Chapter 13 flag removal. Table 5 shows estimates from our parametric difference-in-differences specification that pools the effect across the first, second, and third years after flag removal. Appendix Figure A11 plots the coefficient of interest from our non-parametric specification shown in Equation (1).

In contrast to the financial outcomes, there is no evidence of economically significant effects of flag removal on labor market outcomes, at least for the average bankruptcy filer. At three years after filing, flag removal increases wage employment by a statistically and economically insignificant 0.2 
percentage points on a pre-flag removal mean of 82.0 percent. The 95 percent confidence interval allows us to rule out employment effects larger than about 0.4 percentage points. Similarly, we find that flag removal has virtually no effect on log wages (plus one) with a narrow 95 percent confidence interval. The effect on formal sector employment is statistically distinguishable from zero at a twoyear time horizon, but the magnitudes are economically small both the formal sector employment and earnings outcomes at all of the time horizons.

Flag removal also has no discernible effect on self-employment, and the 95 percent confidence interval allows us to rule out an effect of more than 0.2 percentage points. We similarly estimate an economically and statistically insignificant effect on self-employment earnings (plus one), with the 95 percent confidence interval ruling out effects greater than 3 percent. Not surprisingly, given the null effects for both the formal and self-employment outcomes, we also find no effect of flag removal on the outcomes that combine the formal sector and self-employment measures.

In summary, none of our results suggest economically important effects of flag removal on the labor market outcomes of the average bankruptcy filer. Consistent with our earlier results, there is also no evidence of different pre-trends for any of our labor market outcomes. Thus, our identifying assumption also appears to be valid for these outcomes.

\subsubsection{Interpretation, Heterogeneity Analysis, and Robustness}

Our results thus far have shown that there are no economically important effects of bankruptcy flag removal on labor market outcomes, at least for the average filer. Because of the contrary anecdotal evidence, we conduct a broad set of heterogeneity and sensitivity analyses of these labor market results.

Labor Supply versus Labor Demand: In principle, a zero labor market effect might stem from countervailing effects on labor supply and demand. In particular, since flag removal increases access to credit, it might reduce labor supply through a credit smoothing effect, thereby offsetting any increase in employers' labor demand.

We investigate this theory by exploiting heterogeneity across individuals in the effect of flag removal on credit access. The first form of heterogeneity we use is based on pre-flag removal credit card utilization. It is plausible that individuals with higher pre-flag removal credit card utilization are relatively more credit constrained, and should therefore experience larger increases in credit ac- 
cess and larger decreases in labor supply compared to individuals with lower pre-flag removal credit card utilization. Thus, if our zero labor market effect is explained by a reduction of labor supply, the employment effect should be downward sloping in pre-flag removal credit limits, with larger employment effects for individuals who had low pre-flag removal utilization (and were never credit constrained), and smaller employment effects for individuals who had high levels of pre-flag removal utilization (and were most likely to have reduced their labor supply in response to flag removal).

Panel A of Figure 6 shows results from this heterogeneity analysis. The plot is constructed by estimating the effect of flag removal for groups of individuals defined by the full interaction of state of residence and five-year age bins. We then show a binned scatter plot of the employment effect against the average pre-flag removal utilization rate for each group. The best fit line is based on the underlying group-level data, with each group weighted by the number of underlying observations and standard errors clustered at the state level. There is substantial heterogeneity in pre-flag removal credit card utilization, with rates varying from 65 percent to more than 85 percent across the binned groups. However, the employment response is completely homogeneous across these groups, with the slope of the best fit line statistically indistinguishable from zero.

The second form of heterogeneity we use arises from variation in the size of the effect of flag removal on credit limits. Individuals who receive larger increases in credit limits experience a larger increase in credit access, and should therefore reduce their labor supply more than individuals who receive smaller increases in credit limits. If our zero labor market effects are explained by a reduction of labor supply, the employment effect should be negatively correlated with the credit limit effect, with larger employment effects for individuals who had small credit limit effects (and thus were mainly exposed to an increase in employers' labor demand) and smaller employment effects for individuals who had larger credit limit effects.

Panel B of Figure 6 plots the employment effect against the effect on credit limits, constructed in an analogous manner to Panel A. While there is substantial variation in the change in credit limits across groups, with the size of the effect varying by more than $\$ 6,000$, there is no evidence that the employment effect is negatively correlated with the credit limit effect, with the slope of the best fit line statistically indistinguishable from zero. Taken together, this evidence suggests that an offsetting labor supply effect cannot explain our zero effect for labor market outcomes, and provides evidence that these estimates should be interpreted as a zero average effect of flag removal employers' labor 
demand. ${ }^{25}$

Demographic Heterogeneity: A further consideration is whether the zero effects for the average filer mask positive effects for specific subgroups. In particular, many advocates of restricting employer credit checks have argued that minorities are most likely to suffer adverse labor market consequences from poor credit reports, although it is unclear whether this is because these advocates think derogatory items are more common for this subset of the population or because they think that the casual effect of having a derogatory item is larger for this group.

Table 6 investigates this claim by reporting estimates of the effect of flag removal on formal sector employment for mutually exclusive subsets of the sample determined by the full interaction of gender, race (defined as either white or non-white), and age (defined as either younger or older than 40 years old at flag removal). The effects are economically small for all of the demographic groups and there is no evidence of consistently larger effects for minority groups.

To investigate heterogeneity in the estimates more broadly, Figure 7 plots the estimated effects of flag removal on formal sector employment at three years for 576 mutually exclusive subsamples determined by the full interaction of gender, race, age, and state of filing. The parameter estimates in the histogram are weighted by the number of underlying observations so that estimates from subsamples with a large number of individuals are more prominent. The employment estimates in our sample are precisely and symmetrically clustered around a median value of 0.391 and mean value of 0.371 . The small number of estimates that are statistically significant at the one percent level only accounts for 2.0 percent of the overall sample, only slightly higher than we would have expected from noise alone. ${ }^{26}$ Results are qualitatively similar at different time horizons and for our other labor market outcomes. Thus, while we cannot definitively rule out positive employment effects for every subgroup, these results suggest that any positive outliers are likely to be the result of statistical noise.

Business Cycle Differences: The zero average effect could also mask differences in strong and weak labor markets. For example, it is possible that employers were willing to overlook any blemishes on filers' credit reports during the strong labor market in the first six years of our sample period (i.e. 2002 to 2007). Appendix Figure A12 and Appendix Table A2 investigate this issue by reporting

\footnotetext{
${ }^{25}$ This analysis presumes that the labor market effect is relatively constant across the changes in access to credit-if the effect on labor demand is correlated with the effect on credit access, the results could still be consistent with offsetting labor supply and demand effects.

${ }^{26}$ When we use a five percent criterion for statistical significance, 10.6 percentage of the estimates are statistically significant.
} 
estimates of flag removal for filers whose flags were removed in 2002 to 2007 (the "boom") and for filers whose flags were removed in 2008 to 2011 ("the bust"). The employment effects are statistically indistinguishable across the two time periods, although the point estimates are slightly larger in 2008 to 2011 when labor markets were tighter.

Labor Market Transitions: A related concern is whether the zero average effects mask large effects for individuals on the margin of the labor force. For instance, individuals who are currently unemployed might benefit the most from a bankruptcy flag removal. An analysis that looks at the overall employment rate might miss a positive effect for this group of individuals. To examine the effect on different groups, we define indicator variables for whether someone who had a job in the previous year takes on a new job ("change job"), maintains the same job ("same job"'), or no longer has a job ("end job"). And we define indicators for whether someone who did not have a job in the prior year finds a job ("start job") or continues to be without work ("no job"). Appendix Figure A13 shows trends for these indicators and Table A3 reports parameter estimates from the corresponding difference-in-differences regressions. There are no economically significant effects on any of these outcome variables, and the 95 percent confidence intervals rule out effects larger than 0.2 percentage points for the "start job" transition at a three year time horizon, where one might have expected to see an economically significant effect.

Industry Churn: The zero average effects may also mask churn across industries. For instance, a survey by the Society of Human Resource Management (SHRM, 2010) indicates that credit checks are used more frequently for jobs that involve "fiduciary and financial responsibility," which are concentrated in the finance industry. At the other extreme, federal, state and local agencies are prohibited from considering bankruptcy in a hiring decision. ${ }^{27}$ Appendix Figures A14 shows employment trends by industry and Appendix Table A4 shows the parameter estimates. In short, there is no economically significant evidence of a reallocation of employment towards finance or any other systemic trends in the effects across industries. For the financial industry, we can rule out effects greater than 0.2 percent with 95 percent confidence at any time horizon.

State Bans: In principle, our zero effect might be partially explained by the state bans on credit checks that were introduced in the last few years of our sample (Clifford and Shoag, 2016). In response

\footnotetext{
${ }^{27}$ See, for example: http://www. nolo.com/legal-encyclopedia/will-bankruptcy-affect-my-job-future-employment html.
} 
to fears of discriminatory hiring practices due to credit checks, ten states have banned the practice of credit checks over the past decade (see Appendix Table A5 for a list of states with credit check bans). In states with a ban on credit checks, we would not be surprised to find a non-result of bankruptcy flag removal on employment, as this information is not available to potential employers. To account for this margin, we split our data into three groups: individuals filing in states that never have a ban, individuals filing in states that implement a ban after their flag removal, and individuals filing in states that implement a ban before their flag removal (but after their filing date). Table 7 shows that in all three cases, there is no statistically or economically significant effect of the Chapter 13 flag removal on the probability of formal sector employment. Results are again qualitatively similar for our other labor market outcomes.

Time Horizon: In interpreting the null effects on labor market outcomes, a natural question is whether employers consider a seven-year-old bankruptcy filing to be important relative to other derogatory items that could appear on a job applicant's credit report. The SHRM (2010) survey sheds some light on this matter. Firms were asked, "how many years of credit history are the most influential in your assessment of the job candidate's credit standing?" In response, 33 percent reported focusing on time horizons of "up to 6 or 7 years" and a further 25 percent indicated they considered longer time horizons. Moreover, across industries and occupations, firms report that bankruptcies are one of the most important items they consider, along with whether the consumer had accounts in collection or current outstanding judgments. In contrast, firms did not place much weight on whether the job applicant had medical or education debt or whether they had a foreclosure flag on their report.

In sum, we find zero effect of flag removal on average, and zero effects across numerous time periods and demographic groups, including for minorities, for whom there have been particular concerns about the employment consequences of derogatory credit reports, and following the financial crisis when labor markets were particularly tight. We also find no evidence on employment dynamics, including the "no job" to "any job" transition, where one might expect to see the largest employment response, and we find no evidence that employment shifts towards industries like finance, which use credit checks more frequently to screen applicants. Finally, we find no employment effects in states that did not implement bans on credit checks (or in states that implemented bans). The consistent zero effects across a range of subsamples and labor market outcomes suggests that credit reports do not play a prominent role in employers' hiring decisions. Instead, our results are consistent with em- 
ployers using a broad range of mechanisms to screen job applicants so that the impact of an improved credit report does not have a measurable impact on the margin.

If credit reports do not matter for employment, why do employers purchase this information? There are a number of potential explanations. Perhaps the most straightforward reason is to reduce legal liability and to comply with state-level legal requirements. According to the SHRM (2010) survey, 27 percent of firms report that the primary reason for conducting a credit background check is to reduce legal liability for negligent hiring, and a further seven percent report that the primary reason is to comply with state laws requiring background checks for certain professions (e.g., day care teachers, licensed medical practitioners). A slightly more involved explanation is that credit checks are a less costly way to screen job applicants that counterfactually would have been screened out later in the hiring process. To give a concrete example, suppose that virtually all job applicants who fail a credit check also fail a reference check on performance at prior jobs. However, suppose that a credit check is cheaper to the firm than the reference check. Then it is optimal to conduct and reject applicants based on the credit checks even if exogenously varying the outcome of the credit check has no impact on the hiring decision on the margin. Such a model would also explain the anecdotal evidence cited in the media. It would be natural for people who failed a credit check to attribute their unemployment to their credit report, even though if they had counterfactually passed the credit check, they still would have been denied the job.

\section{Conclusion}

This paper estimates the causal effect of improved credit reports on credit and labor market outcomes. We find that the removal of a Chapter 13 bankruptcy flag leads to large increases in credit scores and both credit card and mortgage borrowing. In sharp contrast, we find a precise zero effect of improved credit reports on employment and earning outcomes. We conclude that credit reports are most important for outcomes where they are the primary source of information used in screening applicants, such as credit card or mortgage borrowing, but are of limited consequence for outcomes where a broad range of additional information is available, such as hiring decisions. Our results also indicate that recent political attempts to limit the use of credit reports by employers are unlikely to affect labor market outcomes, either positively or negatively, for the targeted populations.

There are at least three caveats to our analysis. First, our employment data is measured annually, and job transitions are infrequent occurrences, so any effects of credit worthiness may not be reflected 
over the three year time horizons we currently examine. Second, the zero average effects we estimate for labor market outcomes do not rule out the existence of some groups of individuals who are affected by flag removal. In our heterogeneity analysis, we find economically small, but statistically significant, effects for some subgroups of the population, and so cannot rule out completely the presence of an effect for some subgroups. Finally, the effects of other changes in the creditworthiness, such as the removal of a foreclosure flag or delinquent debt flag, may be different than the effects examined here. While beyond the scope of this paper, estimating the effects of other improvements in creditworthiness is an important area of future work. 


\section{References}

Agarwal, Sumit, Souphala Chomsisengphet, Neale Mahoney, and Johannes Stroebel. 2015. "Do Banks Pass Through Credit Expansions to Consumers Who Want to Borrow?" NBER Working Paper.

Avery, Robert B, Paul S Calem, Glenn B Canner, and Raphael W Bostic. 2003. "An Overview of Consumer Data and Credit Reporting." Federal Reserve Bulletin, 89: 47.

Bos, Marieke, Emily Breza, and Andres Liberman. 2016. “The Labor Market Effects of Credit Market Information." Working Paper.

Bos, Marieke, Susan Carter, and Paige Marta Skiba. 2012. "The Pawn Industry and its Customers: The United States and Europe." Vanderbilt Law and Economics Research Paper, 12(26).

Braucher, Jean, Dov Cohen, and Robert M. Lawless. 2012. “Race, Attorney Influence, and Bankruptcy Chapter Choice." Journal of Empirical Legal Studies, 9(3): 393-429.

CFPB. 2011. "The Impact of Differences Between Consumer- and Creditor-Purchased Credit Scores." Consumer Financial Protection Bureau.

CFPB. 2012. "Key Dimensions and Processes in the U.S. Credit Reporting System: A review of how the nation's largest credit bureaus manage consumer data." Consumer Financial Protection Bureau.

Clifford, Robert, and Daniel Shoag. 2016. “"No More Credit Score” Employer Credit Check Bans and Signal Substitution." Working Paper.

Dobbie, Will, and Jae Song. 2015. "Debt relief and debtor outcomes: Measuring the effects of consumer bankruptcy protection." The American Economic Review, 105(3): 1272-1311.

Dobbie, Will, Paul Goldsmith-Pinkham, and Crystal Yang. 2015. "Consumer Bankruptcy and Financial Health." National Bureau of Economic Research.

FRB. 2007. "Report to the Congress on Credit Scoring and Its Effects on the Availability and Affordability of Credit." Board of Governors of the Federal Reserve System (US).

Gross, David B., and Nicholas S. Souleles. 2002. "Do Liquidity Constraints and Interest Rates Matter for Consumer Behavior? Evidence from Credit Card Data." Quarterly Journal of Economics, 117(1): 149-185.

Gross, Tal, Matthew J Notowidigdo, and Jialan Wang. 2014. "Liquidity Constraints and Consumer Bankruptcy: Evidence from Tax Rebates." Review of Economics and Statistics, 96(3): 431-443.

Gross, Tal, Matthew J. Notowidigdo, and Jialan Wang. 2016. "The Marginal Propensity to Consumer Over the Business Cycle." NBER Working Paper.

Herkenhoff, Kyle, Gordon Phillips, and Ethan Cohen-Cole. 2016. "The Impact of Consumer Credit Access on Employment, Earnings and Entrepreneurship." Working Paper.

Lee, Donghoon, and Wilbert Van der Klaauw. 2010. "An Introduction to the FRBNY Consumer Credit Panel." FRB of New York Staff Report.

Mahoney, Neale. 2015. "Bankruptcy as Implicit Health Insurance." The American Economic Review, 105(2): 710-746.

Musto, David K. 2004. "What Happens When Information Leaves a Market? Evidence from PostBankrutpcy Consumers." The Journal of Business, 77(4): 725-748. 
National Public Radio. 2012. “Bad Credit Reports Affect Job Applicants." National Public Radio http://www.npr.org/2009/08/11/111769999/low-credit-scores-affect-job-applicants.

New York Times. 2013. "Employers Pull Applicants Credit Reports." The New York Times http://www.nytimes.com/2013/05/12/business/employers-pull-applicants-credit-reports.html.

Shorr, Scott. 1994. "Personal Information Contracts: How to Protect Privacy Without Violating the First Amendment." Cornell L. Rev., 80: 1756.

SHRM. 2010. "Background Checking: The Implications of Credit Background Checks on the Decision to Hire or Not to Hire." Society for Human Resource Management.

Staten, Michael. 2014. "Risk-Based Pricing in Consumer Lending." Center for Capital Markets.

Steinberg, Joseph. 2014. "Your Privacy Is Now At Risk From Search Engines - Even If The Law Says Otherwise." Forbes.

White, Michelle. 2007. "Bankruptcy Reform and Credit Cards." Journal of Economic Perspectives, 21(4): 175-199. 
Figure 1: Economic Interpretation of Credit Score

(A) Histogram

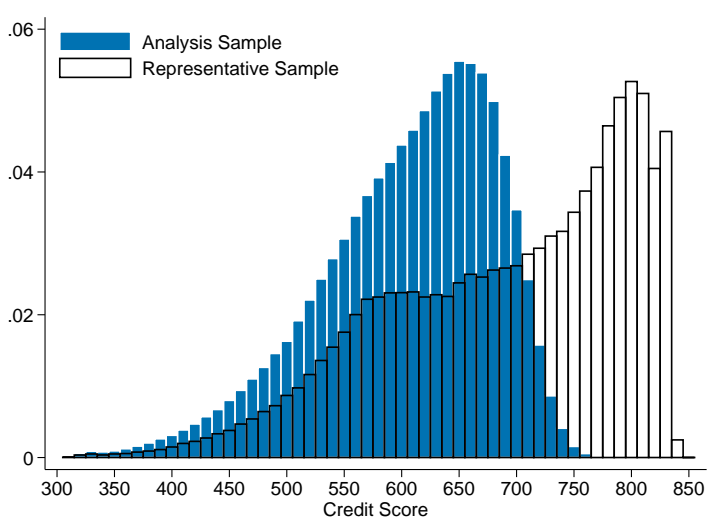

(B) Probability of Default by Credit Score

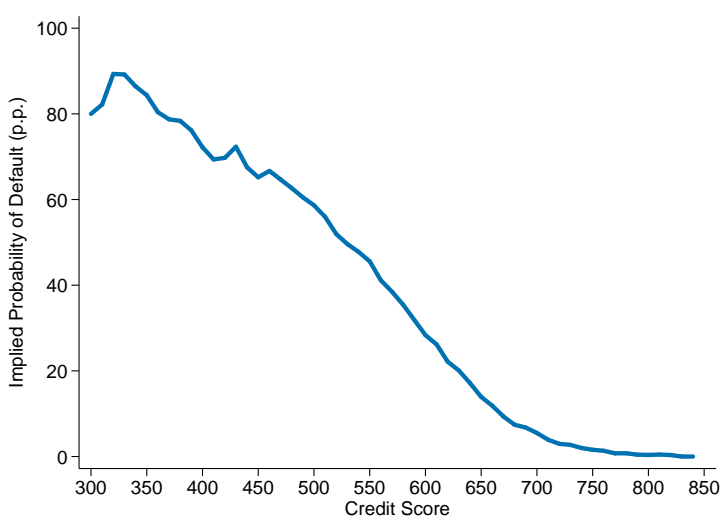

Note: Panel A of this figure plots the distribution of credit scores for a representative sample of the FRBNY Consumer Credit Panel / Equifax data in 2005q1 and the credit scores for our analysis sample of bankruptcy filers 6 years after filing. Panel B of this figure uses the representative sample from Panel A and plots the observed fraction of individuals with a tradeline that is at least 90 days past due (90+ DPD) in $2007 q 1$ against the observed credit score in $2005 q 1$. 


\section{Figure 2: Credit Score Trends}

(A) Credit Score

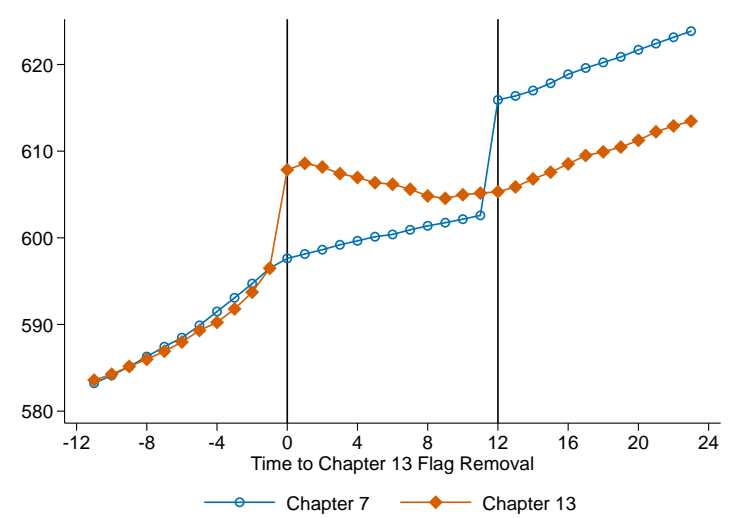

(B) Implied Probability of Default

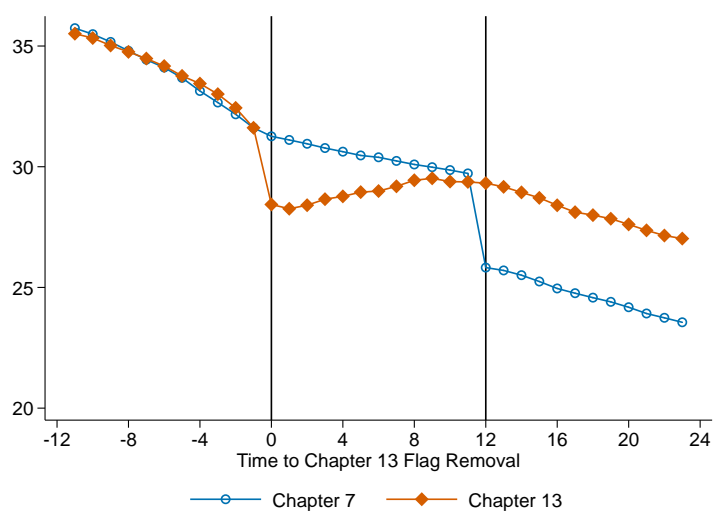

Note: This figure plots average credit scores and the implied probability of default for Chapter 13 and Chapter 7 bankruptcy filers. The horizontal axis denotes time, in quarters, relative to the quarter of Chapter 13 flag removal, which occurs 7 years after filing. The vertical lines show the quarter of Chapter 13 flag removal and the quarter of Chapter 7 flag removal, which occurs 3 years later. Outcomes are normalized to the average value of the outcome for Chapter 13 filers in the quarter prior to flag removal. The sample includes Chapter 13 and Chapter 7 filers who were age 30-54 at the time of Chapter 13 flag removal, successfully completed the bankruptcy process, and had their bankruptcy flag removed sometime between 2002-2011. See the Table 1 notes for additional details on the outcome measures and sample. 


\section{Figure 3: Credit Card Trends}

(A) Credit Card Limits

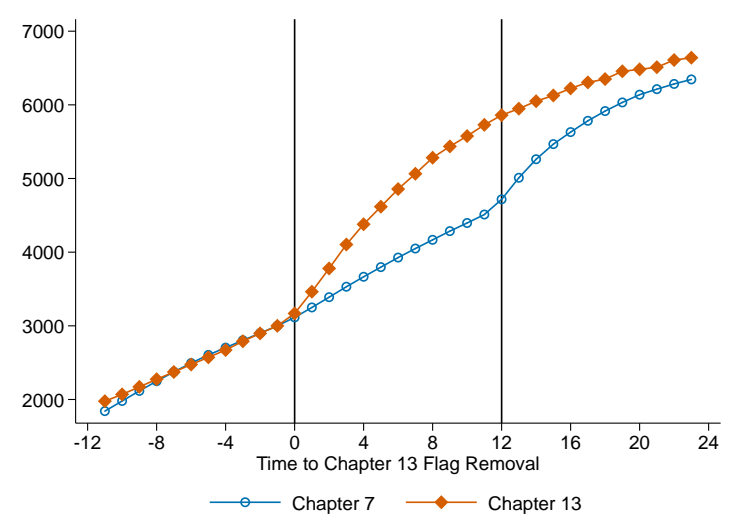

(B) Credit Card Balances

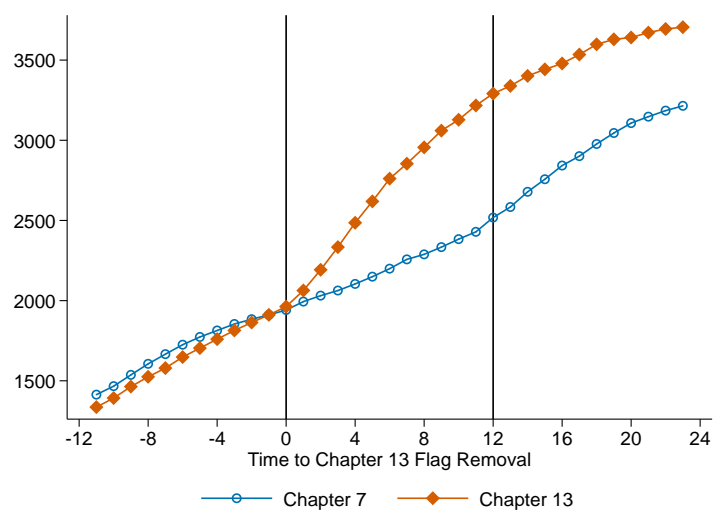

Note: This figure plots the average credit card outcomes for Chapter 13 and Chapter 7 bankruptcy filers. The horizontal axis denotes time, in quarters, relative to the quarter of Chapter 13 flag removal, which occurs 7 years after filing. The vertical lines show the quarter of Chapter 13 flag removal and the quarter of Chapter 7 flag removal, which occurs 3 years later. Outcomes are normalized to the average value of the outcome for Chapter 13 filers in the quarter prior to flag removal. The sample includes Chapter 13 and Chapter 7 filers who were age 30-54 at the time of Chapter 13 flag removal, successfully completed the bankruptcy process, and had their bankruptcy flag removed sometime between 2002-2011. See the Table 1 notes for additional details on the outcome measures and sample. 


\section{Figure 4: Mortgage Trends}

(A) Mortgage Loan

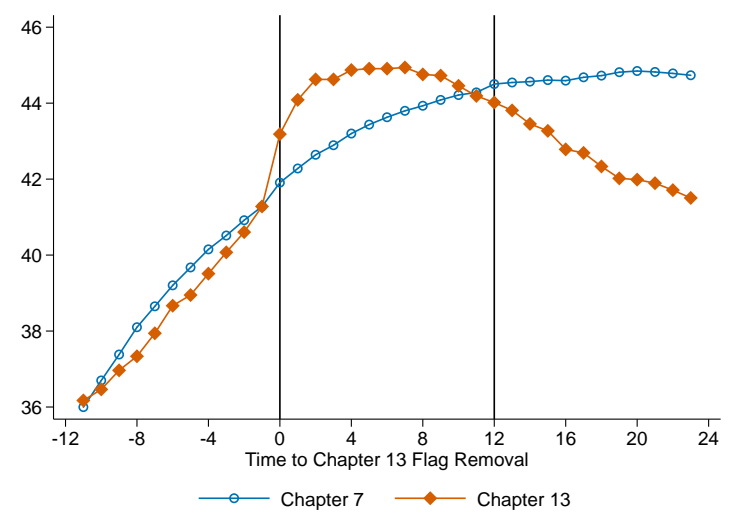

(B) $\log ($ Mortgage Balances +1$)$

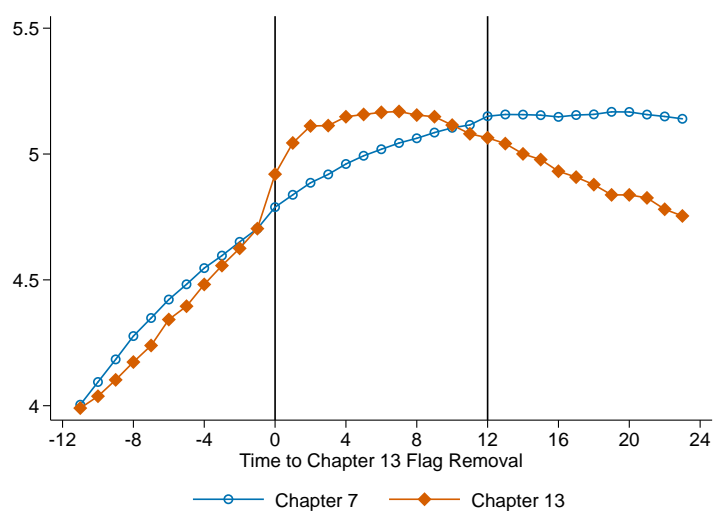

Note: This figure plots the average mortgage outcomes for Chapter 13 and Chapter 7 bankruptcy filers. The horizontal axis denotes time, in quarters, relative to the quarter of Chapter 13 flag removal, which occurs 7 years after filing. The vertical lines show the quarter of Chapter 13 flag removal and the quarter of Chapter 7 flag removal, which occurs 3 years later. Outcomes are normalized to the average value of the outcome for Chapter 13 filers in the quarter prior to flag removal. The sample includes Chapter 13 and Chapter 7 filers who were age 30-54 at the time of Chapter 13 flag removal, successfully completed the bankruptcy process, and had their bankruptcy flag removed sometime between 2002-2011. See the Table 1 notes for additional details on the outcome measures and sample. 


\section{Figure 5: Labor Market Trends}

(A) Wage Employment

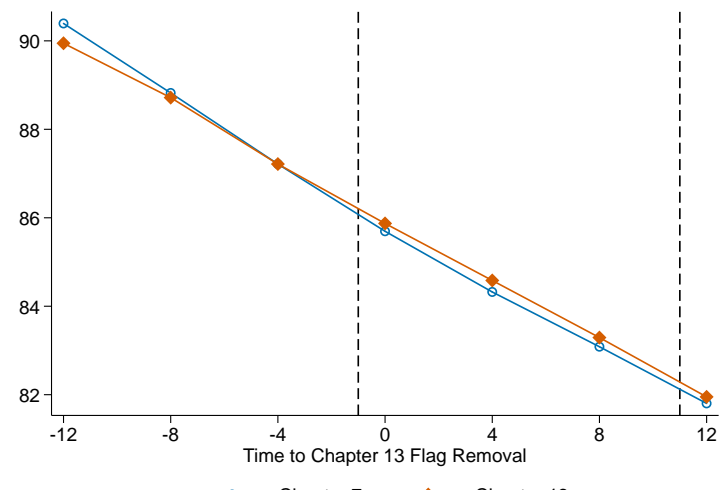

(C) Self-Employment

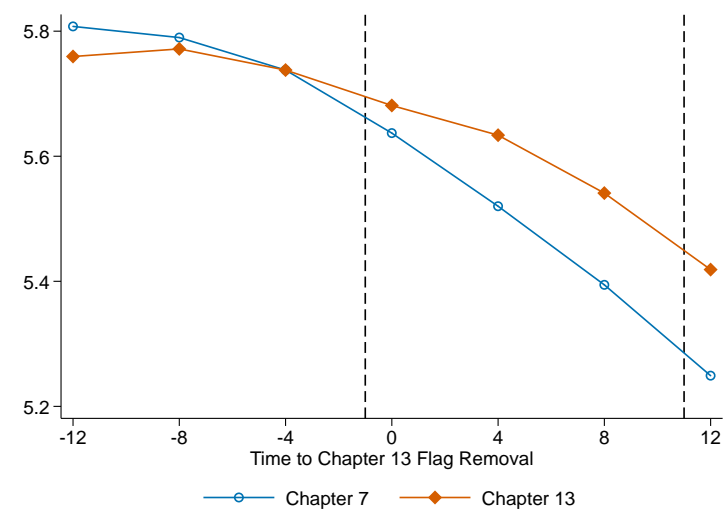

(E) Any Earnings

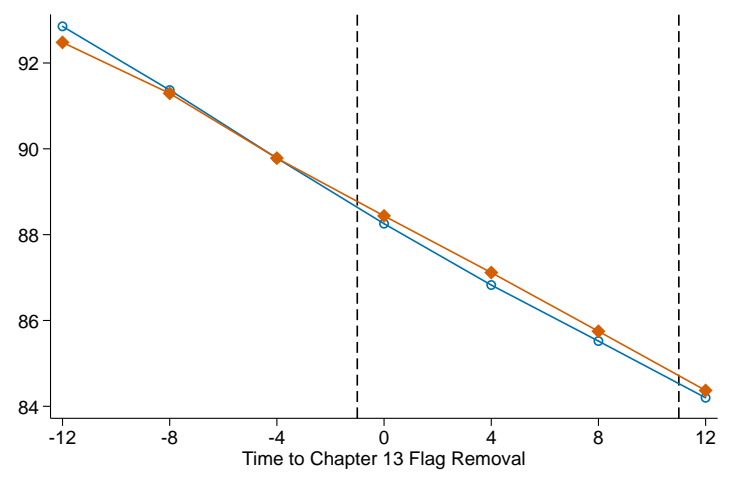

(B) $\log ($ Wage Earnings + 1)

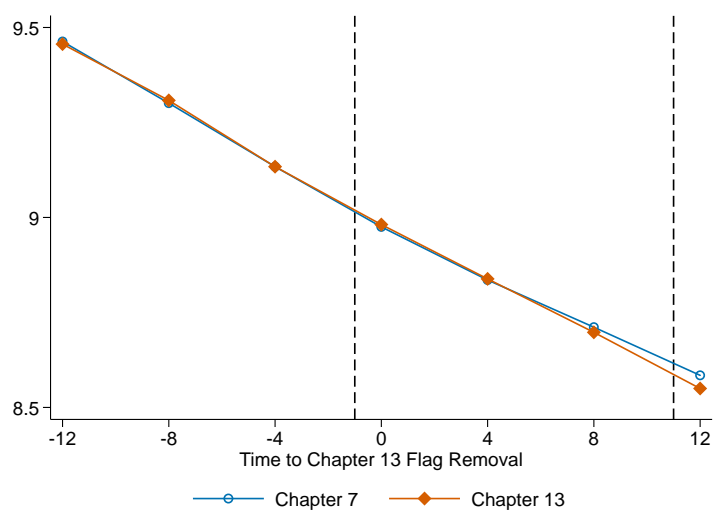

(D) $\log ($ Self Earnings + 1)

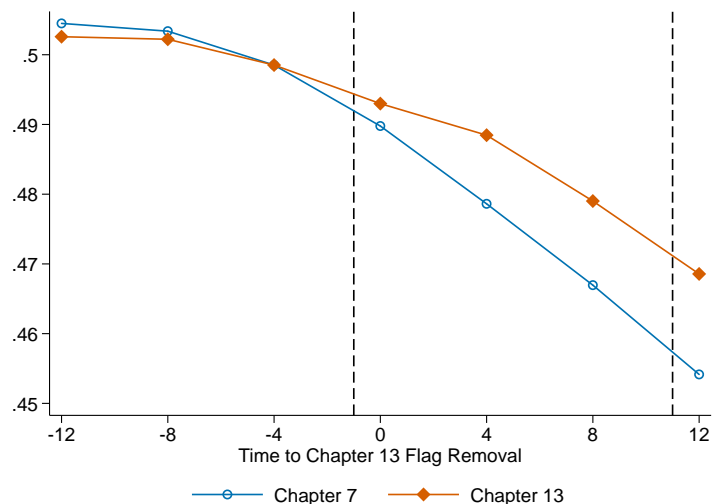

(F) $\log ($ Total Earnings +1$)$

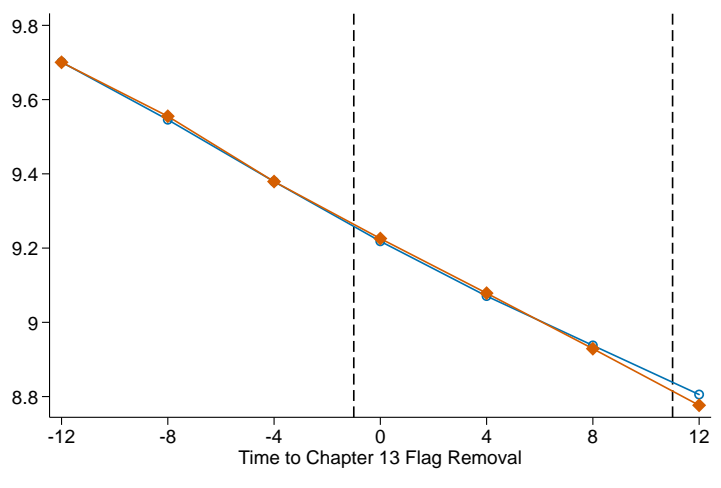

Note: This figure plots the average labor market outcomes for Chapter 13 and Chapter 7 bankruptcy filers. The horizontal axis denotes time, in quarters, relative to the year of Chapter 13 flag removal, which occurs 7 years after filing. The dashed vertical lines show the year of Chapter 13 flag removal and the year Chapter 7 flag removal, which occurs 3 years later. Outcomes are normalized to the average value of the outcome for Chapter 13 filers in the year prior to flag removal. The sample includes Chapter 13 and Chapter 7 filers who were age 30-54 at the time of Chapter 13 flag removal, successfully completed the bankruptcy process, and had their bankruptcy flag removed sometime between 2002-2011. See the Table 1 notes for additional details on the outcome measures and sample. 


\section{Figure 6: Labor Supply versus Labor Demand}

(A) Change in Employment vs. Prior Utilization

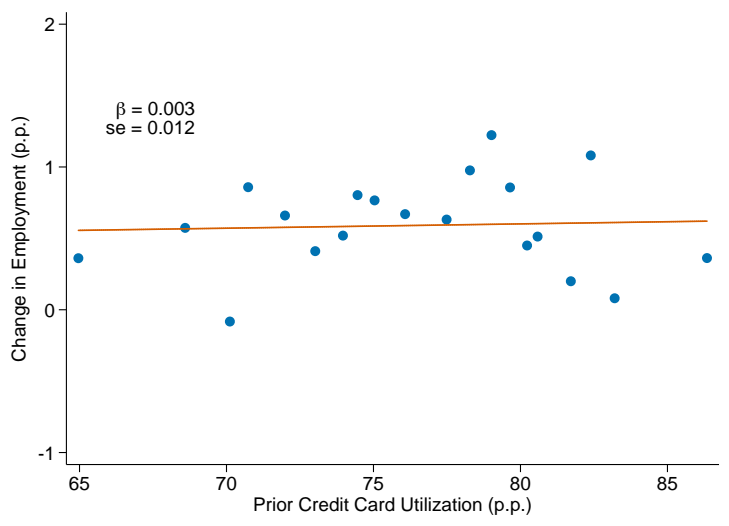

(B) Change in Employment vs. Change in Credit Limits

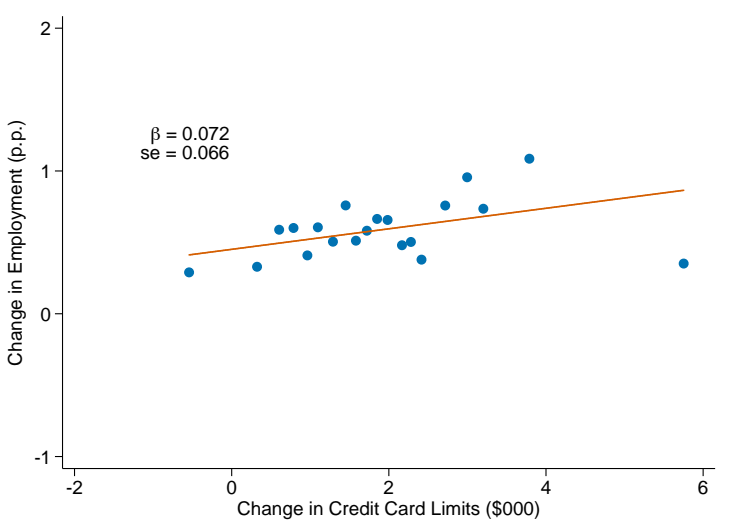

Note: This figure shows binned scatter plots of the estimated coefficients from difference-in-differences regressions conducted at the age group $\times$ state group level. Panel A plots the percentage change in employment against the average credit card utilization rates in $t=-4$ for that age group $\times$ state bin. Panel B plots the percentage change in employment against the change in credit limits. The solid line shows the best linear fit estimated on the underlying age-by-state level data weighted by the number of observations within each group. The coefficients show the estimated slope of the best-fit line, with standard errors clustered at the state level reported below. The effects on employment and credit limits are at one year after flag removal. See the text for additional details on the specification. 
Figure 7: Employment Results by Gender $\times$ Race $\times$ Age $\times$ State

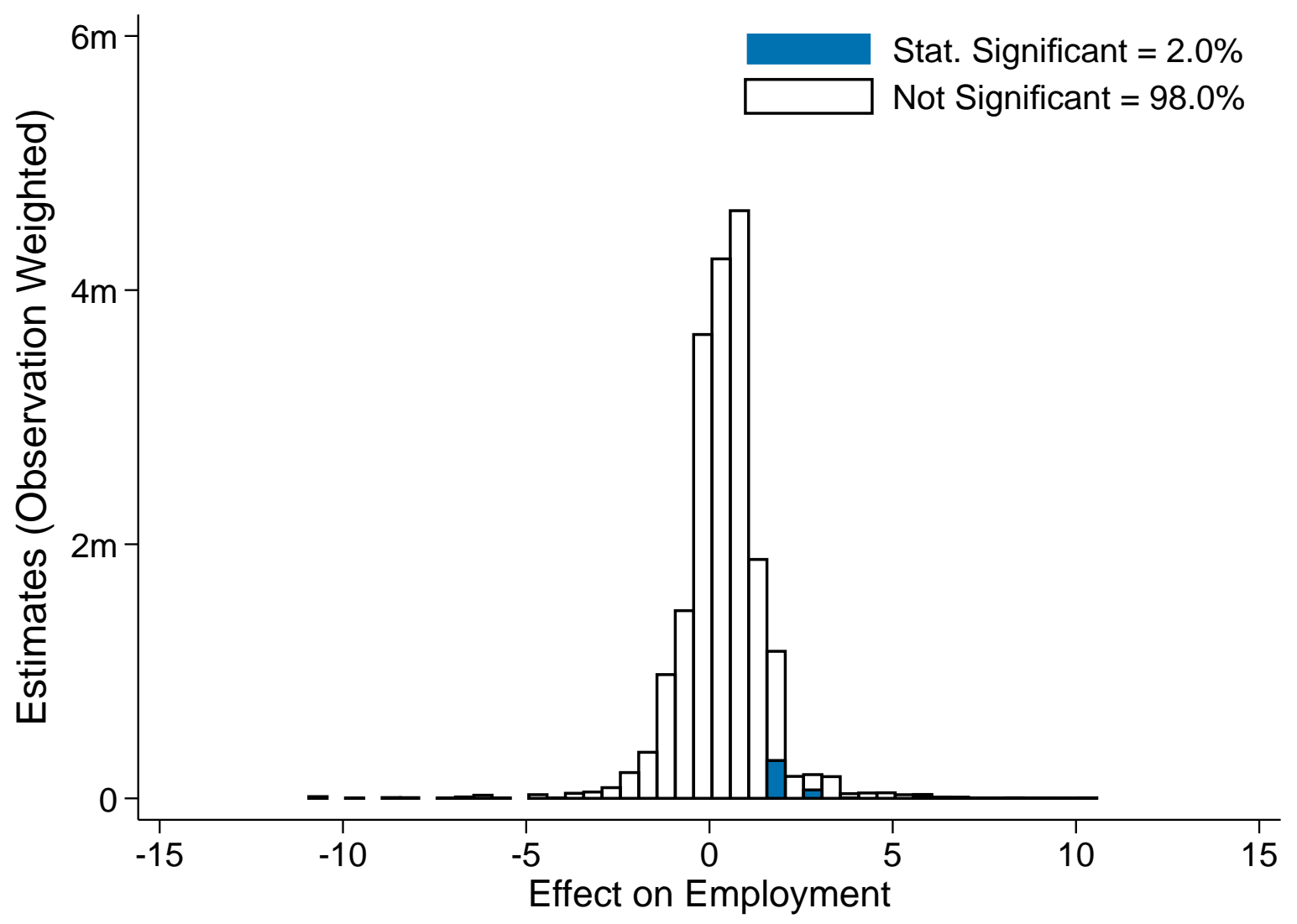

Note: This figure plots the distribution of difference-in-differences estimates for employment at three years at the gender $\times$ race $\times$ age $\times$ state level. We weight each estimate by the number of observations. We also report the fraction of estimates that are statistically significant at the 1 percent level from standard errors clustered at the chapter-by-cohort-by-state level. See the text for additional details on the specification and the Table 1 notes for additional details on the outcome measures and sample. 
Table 1: Summary Statistics

\begin{tabular}{|c|c|c|c|c|c|c|}
\hline & \multicolumn{2}{|c|}{ Chapter 13 Filers } & \multicolumn{2}{|c|}{ Chapter 7 Filers } & \multicolumn{2}{|c|}{ Pooled } \\
\hline & Mean & SD & Mean & SD & Mean & SD \\
\hline Credit Report Data: & $(1)$ & $(2)$ & (3) & (4) & (5) & (6) \\
\hline Credit Score & 597.91 & 83.92 & 603.47 & 78.35 & 603.05 & 78.88 \\
\hline Implied Probability of Default & 31.73 & 20.62 & 29.61 & 20.21 & 29.53 & 20.25 \\
\hline Credit Card Limits & $3,723.49$ & $17,339.53$ & $4,825.85$ & $17,092.70$ & $4,727.96$ & $17,117.63$ \\
\hline Credit Card Balance & $2,156.37$ & $4,411.27$ & $2,818.43$ & 6690.24 & $2,763.04$ & $6,522.90$ \\
\hline Mortgage Loan & 41.64 & 49.30 & 32.57 & 46.86 & 33.37 & 47.16 \\
\hline Log $($ Mortgage Balance +1$)$ & 4.73 & 5.62 & 3.73 & 5.42 & 3.82 & 5.45 \\
\hline \multicolumn{7}{|l|}{ Labor Market Data: } \\
\hline Wage Employment & 85.99 & 28.98 & 80.70 & 32.85 & 81.22 & 32.52 \\
\hline Self-Employment & 5.64 & 18.17 & 6.58 & 19.55 & 6.49 & 19.42 \\
\hline Any Employment & 88.51 & 26.06 & 83.76 & 30.34 & 84.24 & 29.97 \\
\hline Wage Earnings & $39,732.03$ & $31,050.10$ & $33,845.94$ & $31,842.77$ & $34,435.19$ & $31,804.39$ \\
\hline Self-Employment Earnings & 650.71 & $3,655.36$ & 738.75 & $4,205.72$ & 729.94 & $4,153.99$ \\
\hline Total Earnings & $40,382.74$ & $25,737.98$ & $34,584.69$ & $25,645.06$ & $35,165.13$ & $25,712.44$ \\
\hline Log $($ Wages +1$)$ & 9.00 & 3.22 & 8.31 & 3.60 & 8.38 & 3.57 \\
\hline Log(Self-Employment Earnings +1$)$ & 0.49 & 0.57 & 1.75 & 0.08 & 0.56 & 1.74 \\
\hline $\log ($ Earnings +1$)$ & 9.24 & 2.91 & 8.60 & 3.34 & 8.66 & 3.31 \\
\hline
\end{tabular}

Note: This table reports summary statistics. The Chapter 13 sample includes individuals who were age 30-54 at the time of Chapter 13 flag removal, successfully completed the bankruptcy process, and had their bankruptcy flag removed sometime between 2002-2011. The Chapter 7 sample includes individuals with the same characteristics, but whose flag was removed 12 quarters after. All outcomes are measured for the 11 quarters before and after the Chapter 13 flag removal. Credit and mortgage outcomes come from quarterly CCP data. Labor market outcomes come from administrative tax data at the SSA. This quarterly CCP data sample includes 365,798 unique Chapter 7 filers and 35,671 unique Chapter 13 filers for a total of 401,469 unique filers. The SSA sample includes 4,221,999 unique Chapter 7 filers and 469,676 unique Chapter 13 filers for a total of 4,691,675 filers. Credit Score is the Equifax Risk Score 3.0 measure, described in the text. Implied Probability of Default is the estimated probability of having a 90+ day delinquent loan two years later. Credit Card Limits and Credit Card Balance are calculated as the sum of bank card and retail card lines of credit. Mortgage Loan is an indicator for having a mortgage loan. Employment is an indicator for non-zero wage earnings, self-employment is an indicator for non-zero self-employment earnings, and any employment is an indicator for non-zero wage or self-employment earnings. All indicator measures are scaled by 100 to calculate percentages. 
Table 2: Effect of Chapter 13 Flag Removal on Credit Scores

\begin{tabular}{|c|c|c|c|c|}
\hline & \multirow{2}{*}{$\begin{array}{c}\text { Mean at } \\
t=-1\end{array}$} & \multicolumn{3}{|c|}{ Difference-in-Differences Estimates } \\
\hline & & 1 Year & 2 Years & 3 Years \\
\hline & $(1)$ & $(2)$ & (3) & $(4)$ \\
\hline Credit Score & $\begin{array}{l}596.49 \\
(77.29)\end{array}$ & $\begin{array}{l}9.76^{* * *} \\
(0.32)\end{array}$ & $\begin{array}{l}6.31^{* * *} \\
(0.50)\end{array}$ & $\begin{array}{l}3.16^{* * *} \\
(0.65)\end{array}$ \\
\hline Implied Probability of Default & $\begin{array}{c}31.61 \\
(20.05)\end{array}$ & $\begin{array}{c}-2.63^{* * *} \\
(0.10)\end{array}$ & $\begin{array}{c}-1.55^{* * *} \\
(0.15)\end{array}$ & $\begin{array}{c}-0.56^{* * *} \\
(0.19)\end{array}$ \\
\hline
\end{tabular}

Note: This table reports difference-in-differences estimates of the effect of Chapter 13 bankruptcy flag removal on credit scores. Column 1 reports the dependent variable mean and standard deviation for Chapter 13 filers in the quarter prior to flag removal. Columns 2-4 report coefficients on the effect of flag removal from 0-3, 4-7, and 8-11 quarters, respectively. The sample includes Chapter 13 and Chapter 7 filers who were age 30-54 at the time of Chapter 13 flag removal, successfully completed the bankruptcy process, and had their bankruptcy flag removed sometime between 2002-2011. The regressions include $23,772,930$ person-year-quarter observations for 401,469 unique individuals. Standard errors, in parentheses, are clustered at the chapter-by-cohort-year-by-state level. ${ }^{* * *}=$ significant at 1 percent level, ${ }^{* *}=$ significant at 5 percent level, ${ }^{*}=$ significant at 10 percent level. See the text for additional details on the specification and the Table 1 notes for additional details on the outcome measures and sample. 


\section{Table 3: Effect of Chapter 13 Flag Removal on Credit Card Outcomes}

\begin{tabular}{cccccc}
\hline & Mean at & & \multicolumn{3}{c}{ Difference-in-Differences Estimates } \\
\cline { 2 - 2 } \cline { 5 - 6 } \cline { 5 - 6 } Credit Card Limits & $t=-1$ & & 1 Year & 2 Years & 3 Years \\
\cline { 2 - 3 } \cline { 5 - 6 } Credit Card Balance & $3,027.44$ & & $382.32^{* * *}$ & $1,093.67^{* * *}$ & $1,509.58^{* * *}$ \\
& $(5,379.76)$ & & $(38.09)$ & $(84.49)$ & $(108.94)$ \\
& $1,911.02$ & & $143.19^{* * *}$ & $538.32^{* * *}$ & $799.76^{* * *}$ \\
& $(3,538.36)$ & & $(17.25)$ & $(37.06)$ & $(52.25)$ \\
\hline
\end{tabular}

Note: This table reports difference-in-differences estimates of the effect of Chapter 13 bankruptcy flag removal on credit card outcomes. Column 1 reports the dependent variable mean and standard deviation for Chapter 13 filers in the quarter prior to flag removal. Columns 2-4 report coefficients on the effect of flag removal from $0-3,4-7$, and 8-11 quarters, respectively. The sample includes Chapter 13 and Chapter 7 filers who were age 30-54 at the time of Chapter 13 flag removal, successfully completed the bankruptcy process, and had their bankruptcy flag removed sometime between 2002-2011. The regressions include 23,772,930 person-year-quarter observations for 401,469 unique individuals. Standard errors, in parentheses, are clustered at the chapter-by-cohort-year-by-state level. ${ }^{* *}=$ significant at 1 percent level, ${ }^{* *}=$ significant at 5 percent level, ${ }^{*}=$ significant at 10 percent level. See the text for additional details on the specification and the Table 1 notes for additional details on the outcome measures and sample. 
Table 4: Effect of Chapter 13 Flag Removal on Mortgage Outcomes

\begin{tabular}{|c|c|c|c|c|}
\hline & \multirow{2}{*}{$\begin{array}{c}\text { Mean at } \\
t=-1\end{array}$} & \multicolumn{3}{|c|}{ Difference-in-Differences Estimates } \\
\hline & & 1 Year & 2 Years & 3 Years \\
\hline & (1) & (2) & (3) & (4) \\
\hline Mortgage Loan & $\begin{array}{c}41.28 \\
(49.23)\end{array}$ & $\begin{array}{l}1.87^{* * *} \\
(0.22)\end{array}$ & $\begin{array}{l}1.80^{* * *} \\
(0.27)\end{array}$ & $\begin{array}{l}1.00^{* * *} \\
(0.31)\end{array}$ \\
\hline Log(Mortgage Balance +1$)$ & $\begin{array}{c}4.70 \\
(5.62)\end{array}$ & $\begin{array}{c}0.21^{* * *} \\
(0.03)\end{array}$ & $\begin{array}{l}0.21^{* * *} \\
(0.03)\end{array}$ & $\begin{array}{l}0.11^{* * *} \\
(0.04)\end{array}$ \\
\hline
\end{tabular}

Note: This table reports difference-in-differences estimates of the effect of Chapter 13 bankruptcy flag removal on mortgage outcomes. Column 1 reports the dependent variable mean and standard deviation for Chapter 13 filers in the quarter prior to flag removal. Columns 2-4 report coefficients on the effect of flag removal from 0-3, 4-7, and 8-11 quarters, respectively. The sample includes Chapter 13 and Chapter 7 filers who were age 30-54 at the time of Chapter 13 flag removal, successfully completed the bankruptcy process, and had their bankruptcy flag removed sometime between 2002-2011. The regressions include 23,772,930 person-year-quarter observations for 401,469 unique individuals. Standard errors, in parentheses, are clustered at the chapter-by-cohort-year-by-state level. ${ }^{* *}=$ significant at 1 percent level, ${ }^{* *}=$ significant at 5 percent level, ${ }^{*}=$ significant at 10 percent level. See the text for additional details on the specification and the Table 1 notes for additional details on the outcome measures and sample. 
Table 5: Effect of Chapter 13 Flag Removal on Labor Market Outcomes

\begin{tabular}{|c|c|c|c|c|}
\hline & \multirow{2}{*}{$\begin{array}{c}\text { Mean at } \\
t=-1\end{array}$} & \multicolumn{3}{|c|}{ Difference-in-Differences Estimates } \\
\hline & & 1 Year & 2 Years & 3 Years \\
\hline & $(1)$ & $(2)$ & (3) & $(4)$ \\
\hline \multirow[t]{2}{*}{ Wage Employment } & 82.02 & 0.16 & $0.23^{* *}$ & 0.17 \\
\hline & $(19.90)$ & $(0.11)$ & $(0.11)$ & $(0.11)$ \\
\hline \multirow[t]{2}{*}{ Self-Employment } & 6.66 & 0.02 & 0.07 & 0.09 \\
\hline & $(3.79)$ & $(0.06)$ & $(0.05)$ & $(0.06)$ \\
\hline \multirow[t]{2}{*}{ Any Employment } & 85.13 & 0.15 & $0.24^{* *}$ & 0.16 \\
\hline & $(16.52)$ & $(0.12)$ & $(0.12)$ & $(0.11)$ \\
\hline \multirow{2}{*}{ Log(Wages + 1) } & 8.45 & 0.00 & -0.00 & -0.02 \\
\hline & $(2.07)$ & $(0.01)$ & $(0.01)$ & $(0.01)$ \\
\hline \multirow[t]{2}{*}{ Log(Self-Employment Earnings +1$)$} & 0.58 & 0.00 & 0.01 & 0.01 \\
\hline & $(0.36)$ & $(0.00)$ & $(0.00)$ & $(0.01)$ \\
\hline \multirow[t]{2}{*}{$\log ($ Earnings +1$)$} & 8.75 & 0.00 & 0.00 & -0.02 \\
\hline & $(1.75)$ & $(0.01)$ & $(0.01)$ & $(0.01)$ \\
\hline
\end{tabular}

Note: This table reports difference-in-differences estimates of the effect of Chapter 13 bankruptcy flag removal on labor market outcomes. Column 1 reports the dependent variable mean and standard deviation for Chapter 13 filers in the year prior to flag removal. Columns 2-4 report coefficients on the effect of flag removal for years 1-3. The sample includes Chapter 13 and Chapter 7 filers who were age 30-54 at the time of Chapter 13 flag removal, successfully completed the bankruptcy process, and had their bankruptcy flag removed sometime between 2002-2011. The regressions include 32,797,030 person-year observations for 4,691,675 unique individuals. Standard errors, in parentheses, are clustered at the chapter-by-cohort-bystate level. ${ }^{* * *}=$ significant at 1 percent level, ${ }^{* *}=$ significant at 5 percent level, ${ }^{*}=$ significant at 10 percent level. See the text for additional details on the specification and the Table 1 notes for additional details on the outcome measures and sample. 
Table 6: Employment Results by Filer Characteristics

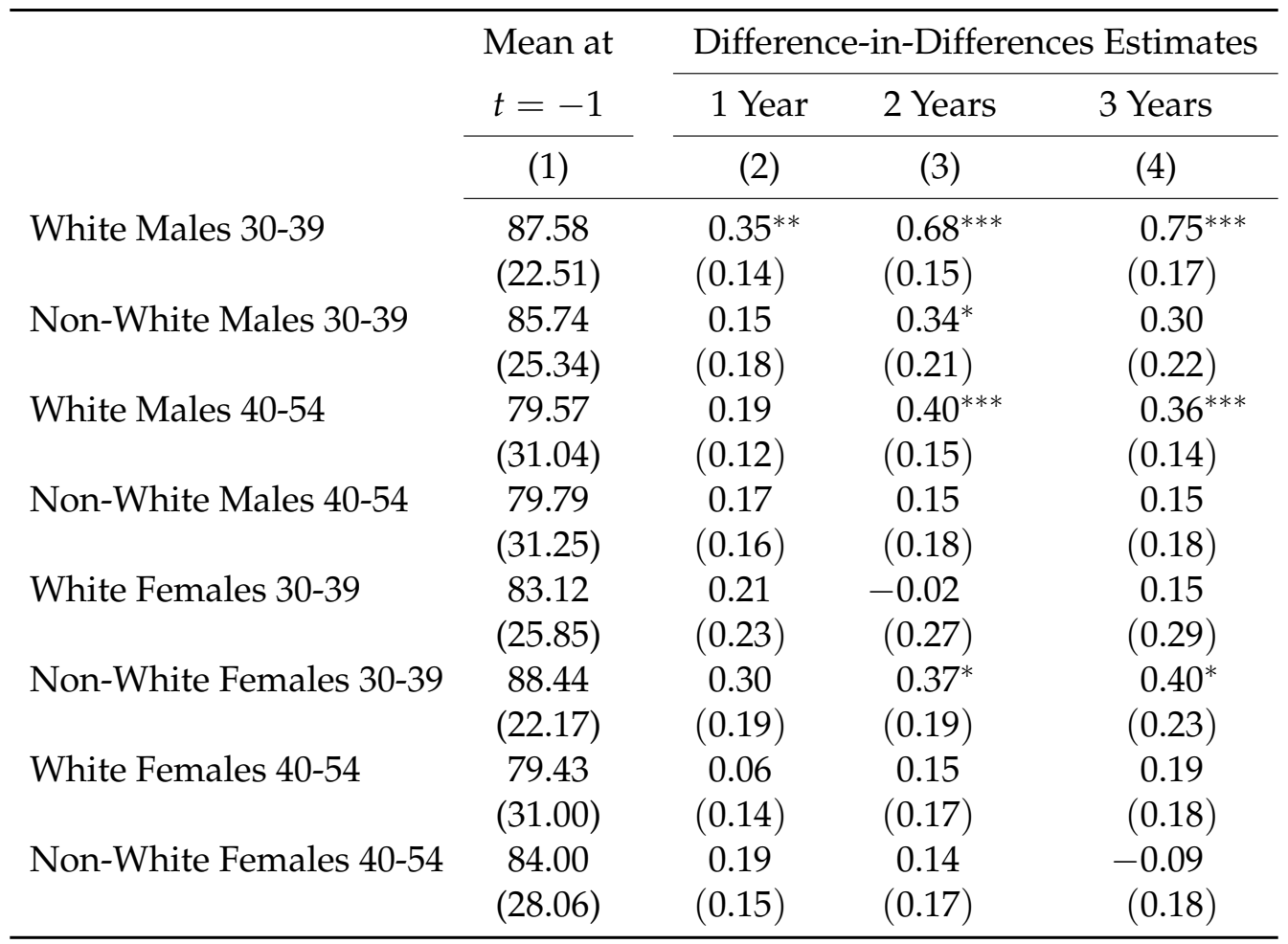

Note: This table reports difference-in-differences estimates of the effect of Chapter 13 bankruptcy flag removal separately by borrower subgroup. Column 1 reports the dependent variable mean and standard deviation for Chapter 13 filers in the year prior to flag removal. Columns 2-4 report coefficients on the effect of flag removal for years 1-3. The sample includes Chapter 13 and Chapter 7 filers who were age 30-54 at the time of Chapter 13 flag removal, successfully completed the bankruptcy process, and had their bankruptcy flag removed sometime between 2002-2011. The regressions include 32,797,030 person-year observations for 4,691,675 unique individuals. Standard errors, in parentheses, are clustered at the chapter-by-cohort-by-state level. ${ }^{* * *}=$ significant at 1 percent level, ${ }^{* *}=$ significant at 5 percent level, ${ }^{*}=$ significant at 10 percent level. See the text for additional details on the specification and the Table 1 notes for additional details on the outcome measures and sample. 
Table 7: Employment Results and State Bans on Credit Checks for Employment

\begin{tabular}{|c|c|c|c|c|}
\hline & \multirow{2}{*}{$\begin{array}{c}\text { Mean at } \\
t=-1\end{array}$} & \multicolumn{3}{|c|}{ Difference-in-Differences Estimates } \\
\hline & & 1 Year & 2 Years & 3 Years \\
\hline & (1) & (2) & (3) & (4) \\
\hline \multirow[t]{2}{*}{ States with No Ban } & 82.07 & 0.17 & $0.23^{*}$ & 0.19 \\
\hline & $(18.41)$ & $(0.11)$ & $(0.12)$ & $(0.12)$ \\
\hline \multirow[t]{2}{*}{ Pre-Ban in States with Ban } & 82.03 & 0.15 & 0.30 & 0.16 \\
\hline & $(28.73)$ & $(0.31)$ & $(0.31)$ & $(0.31)$ \\
\hline \multirow[t]{2}{*}{ Post-Ban in States with Ban } & 79.40 & -0.62 & -0.62 & -0.76 \\
\hline & $(28.87)$ & $(0.49)$ & $(0.48)$ & $(0.51)$ \\
\hline
\end{tabular}

Note: This table reports difference-in-differences estimates of the effect of Chapter 13 bankruptcy flag removal separately for states with and without bans on credit checks for employment. Column 1 reports the dependent variable mean and standard deviation for Chapter 13 filers in the year prior to flag removal. Columns 2-4 report coefficients on the effect of flag removal for years 1-3. The sample includes Chapter 13 and Chapter 7 filers who were age 30-54 at the time of Chapter 13 flag removal, successfully completed the bankruptcy process, and had their bankruptcy flag removed sometime between 2002-2011. The regressions include 32,797,030 person-year observations for 4,691,675 unique individuals. Standard errors, in parentheses, are clustered at the chapter-bycohort-by-state level. $^{* * *}=$ significant at 1 percent level, ${ }^{* *}=$ significant at 5 percent level, ${ }^{*}=$ significant at 10 percent level. See the text for additional details on the specification and the Table 1 notes for additional details on the outcome measures and sample. 


\section{Bad Credit, No Problem? Credit and Labor Market Consequences of Bad Credit Reports \\ Online Appendix}

Will Dobbie Paul Goldsmith-Pinkham Neale Mahoney Jae Song 
Figure A1: Effect of Chapter 13 Flag Removal on Credit Scores

(A) Credit Score

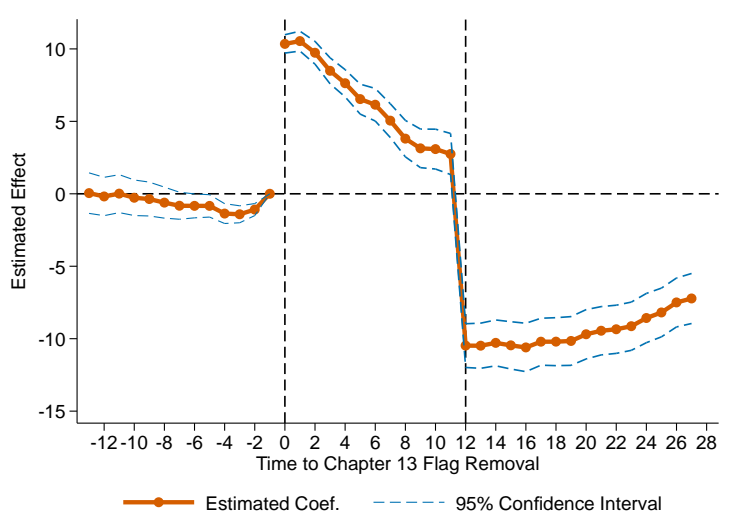

(B) Implied Probability of Default

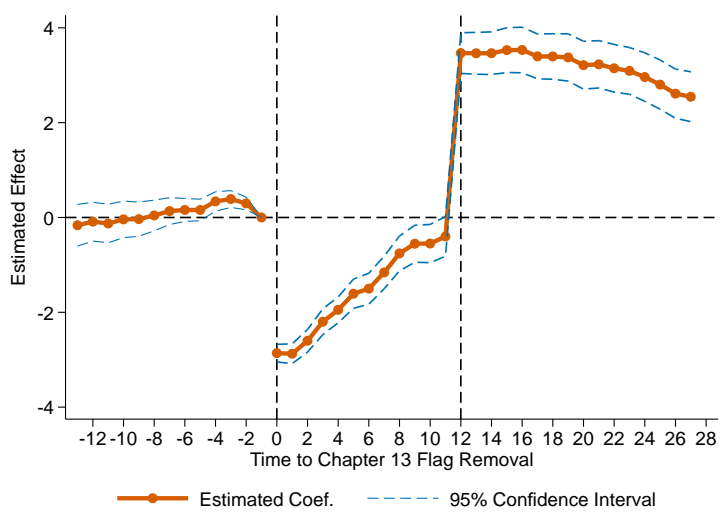

Note: This figure plots difference-in-differences estimates of the effect of Chapter 13 bankruptcy flag removal on credit scores. The horizontal axis denotes time, in quarters, relative to the quarter of Chapter 13 flag removal, which occurs 7 years after filing. The dashed vertical lines show the quarter of Chapter 13 flag removal and the quarter of Chapter 7 flag removal, which occurs 3 years later. The estimated effect is normalized to zero in the quarter before Chapter 13 flag removal period. The dashed lines are 95 percent confidence intervals from standard errors clustered at the chapter-by-cohort-by-state level. See the text for additional details on the specification and the Table 1 notes for additional details on the outcome measures and sample. 


\section{Figure A2: Credit Score Trends by Pre-Flag Removal Credit Score}

(A) Bottom Quartile

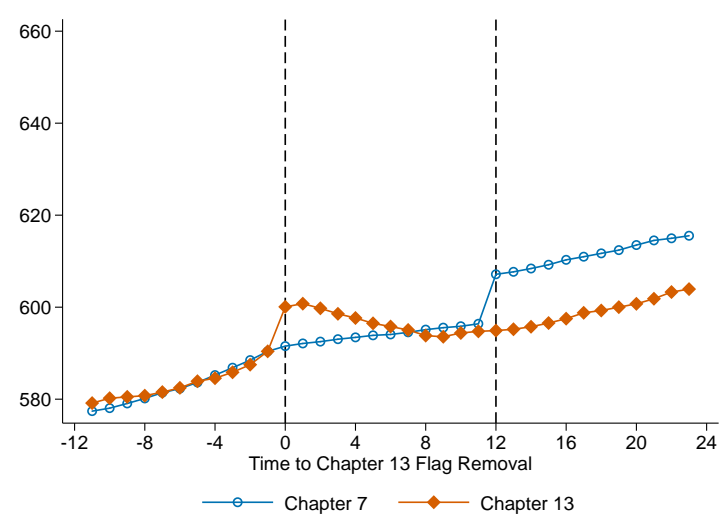

(C) Third Quartile

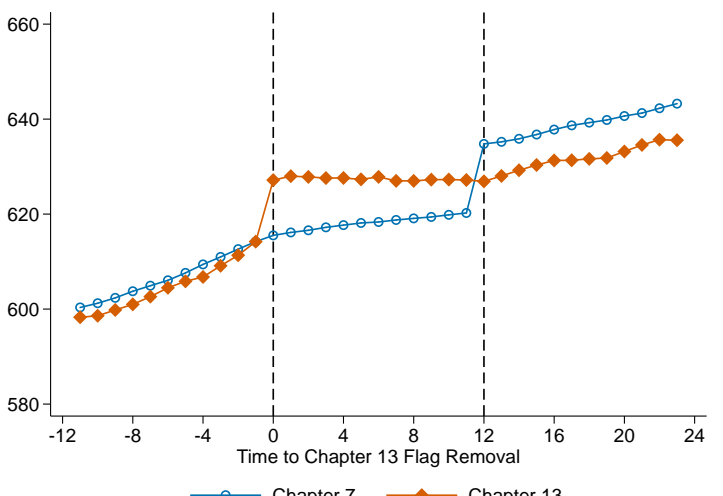

(B) Second Quartile

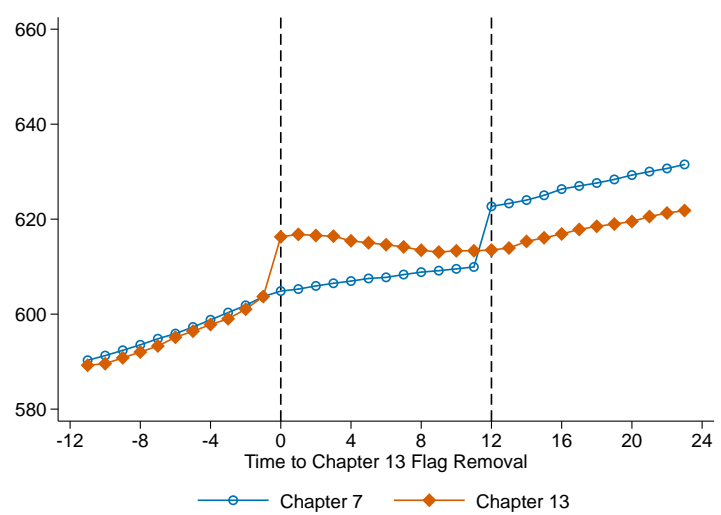

(D) Top Quartile

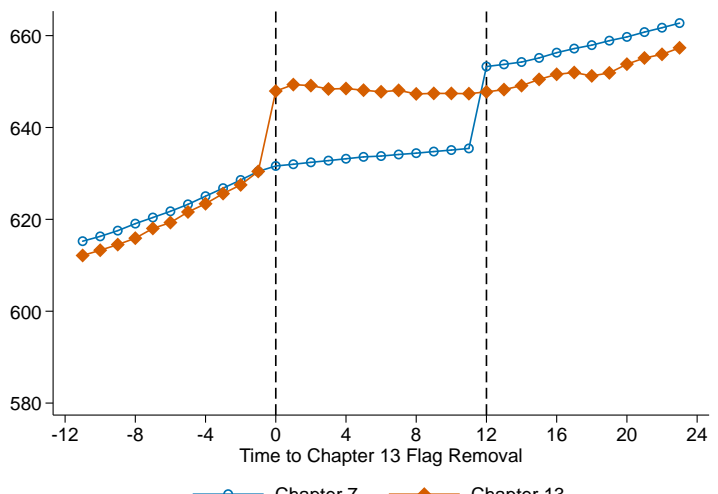

Note: This figure plots average credit scores for Chapter 13 and Chapter 7 bankruptcy filers by predicted preflag removal credit score. We construct pre-removal credit scores from a linear regression of pre-flag removal credit score on five-year age buckets and state fixed effects. The horizontal axis denotes time, in quarters, relative to the quarter of Chapter 13 flag removal, which occurs 7 years after filing. The dashed vertical lines show the quarter of Chapter 13 flag removal and the quarter of Chapter 7 flag removal, which occurs 3 years later. Outcomes are normalized to the average value of the outcome for Chapter 13 filers in the quarter prior to flag removal. The sample includes Chapter 13 and Chapter 7 filers who were age 30-54 at the time of Chapter 13 flag removal, successfully completed the bankruptcy process, and had their bankruptcy flag removed sometime between 2002-2011. See the Table 1 notes for additional details on the outcome measures and sample. 


\section{Figure A3: Implied Probability of Default by Pre-Flag Removal Credit Score}

(A) Bottom Quartile

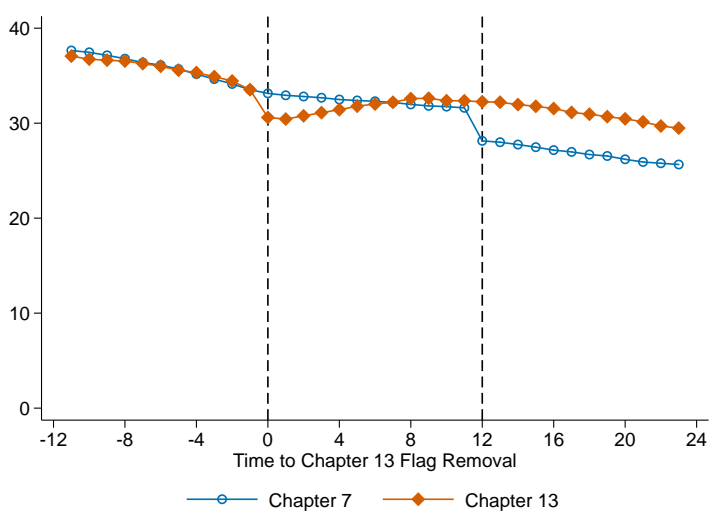

(C) Third Quartile

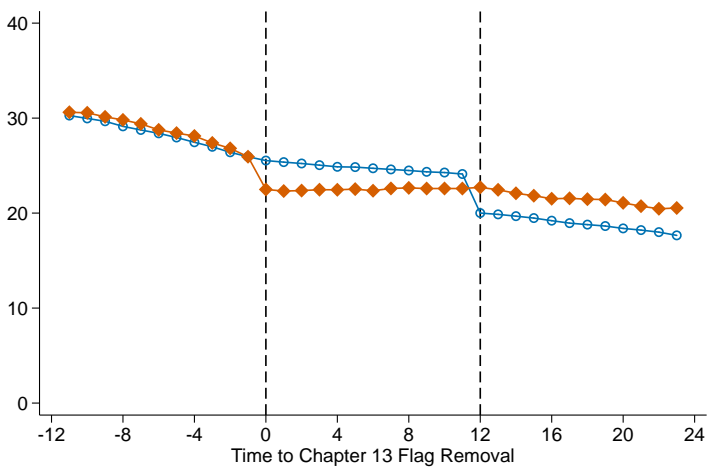

$\longrightarrow$ Chapter $7 \longrightarrow$ Chapter 13
(B) Second Quartile

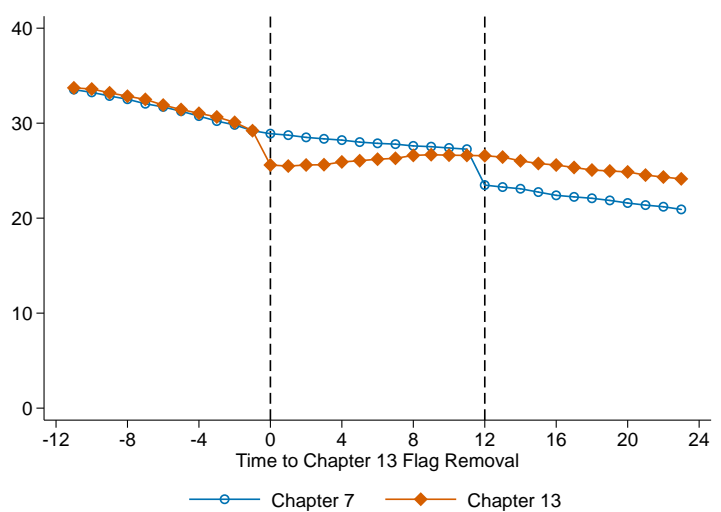

(D) Top Quartile

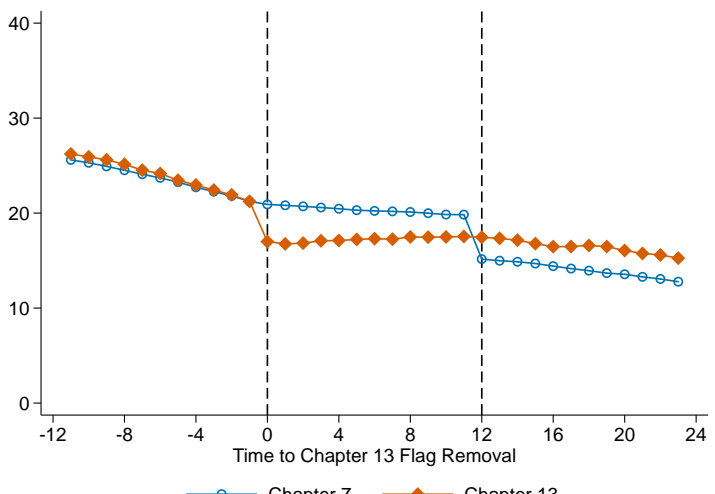

Note: This figure plots average credit scores for Chapter 13 and Chapter 7 bankruptcy filers by predicted preflag removal credit score. We construct pre-removal credit scores from a linear regression of pre-flag removal credit score on five-year age buckets and state fixed effects. The horizontal axis denotes time, in quarters, relative to the quarter of Chapter 13 flag removal, which occurs 7 years after filing. The dashed vertical lines show the quarter of Chapter 13 flag removal and the quarter of Chapter 7 flag removal, which occurs 3 years later. Outcomes are normalized to the average value of the outcome for Chapter 13 filers in the quarter prior to flag removal. The sample includes Chapter 13 and Chapter 7 filers who were age 30-54 at the time of Chapter 13 flag removal, successfully completed the bankruptcy process, and had their bankruptcy flag removed sometime between 2002-2011. See the Table 1 notes for additional details on the outcome measures and sample. 


\section{Figure A4: Effect of Chapter 13 Flag Removal on Credit Card Outcomes}

\section{(A) Credit Card Limits}

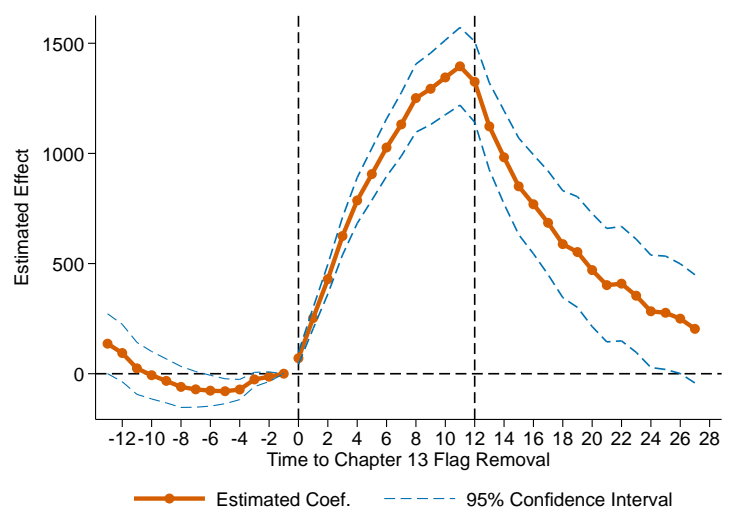

(B) Credit Card Balances

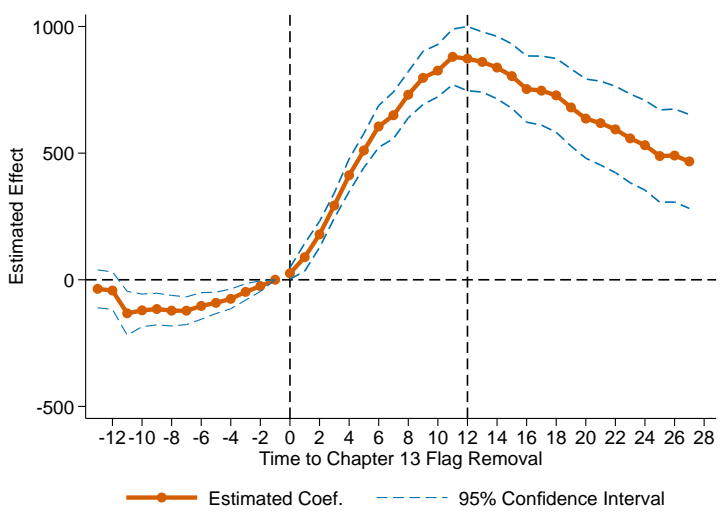

Note: This figure plots difference-in-differences estimates of the effect of Chapter 13 bankruptcy flag removal on credit card outcomes. The horizontal axis denotes time, in quarters, relative to the quarter of Chapter 13 flag removal, which occurs 7 years after filing. The dashed vertical lines show the quarter of Chapter 13 flag removal and the quarter of Chapter 7 flag removal, which occurs 3 years later. The estimated effect is normalized to zero in the quarter before Chapter 13 flag removal period. The dashed lines are 95 percent confidence intervals from standard errors clustered at the chapter-by-cohort-by-state level. See the text for additional details on the specification and the Table 1 notes for additional details on the outcome measures and sample. 


\section{Figure A5: Credit Card Limits by Pre-Flag Removal Credit Score}

(A) Bottom Quartile

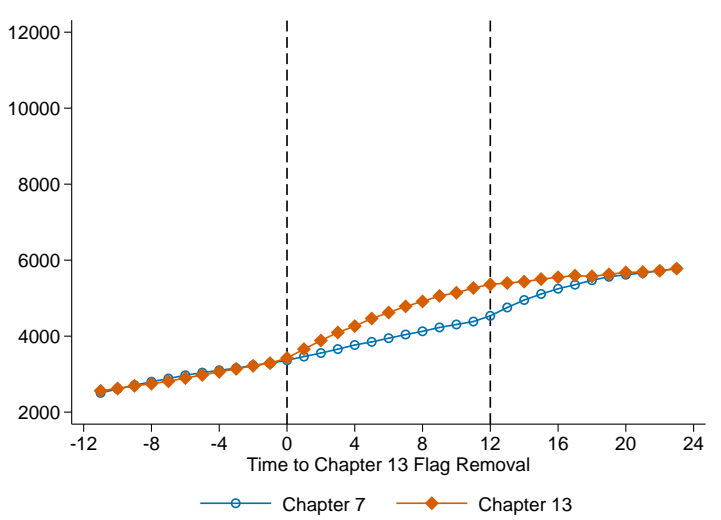

(A) Third Quartile

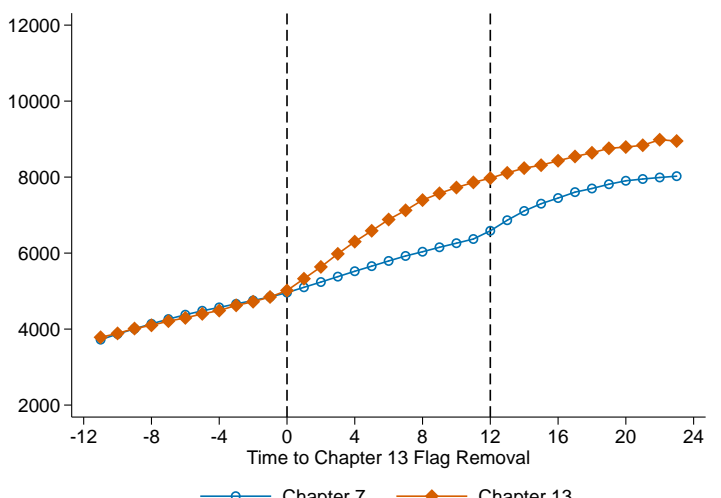

(B) 2nd Quartile

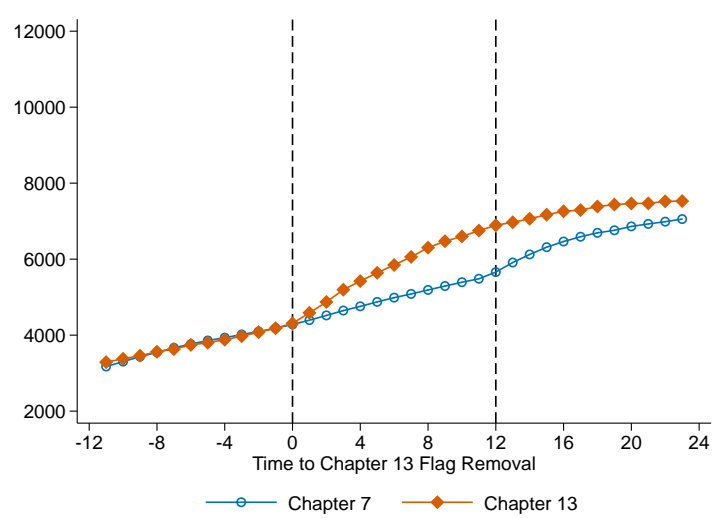

(B) Top Quartile

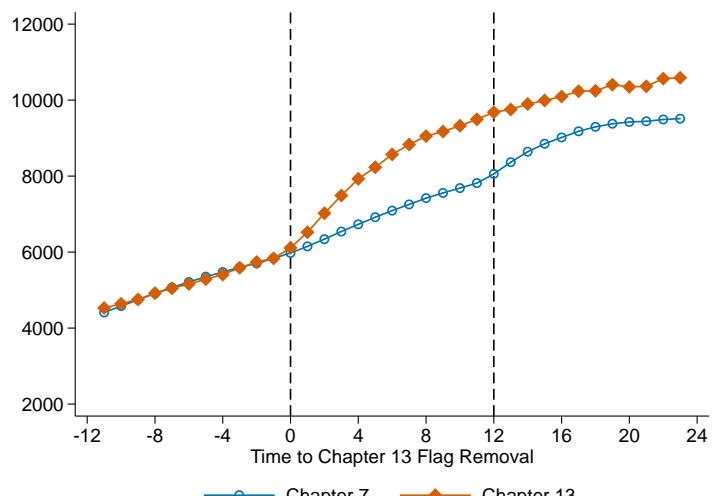

Note: This figure plots average credit card limits for Chapter 13 and Chapter 7 bankruptcy filers by predicted pre-flag removal credit score. We construct pre-removal credit scores from a linear regression of pre-flag removal credit score on five-year age buckets and state fixed effects. The horizontal axis denotes time, in quarters, relative to the quarter of Chapter 13 flag removal, which occurs 7 years after filing. The dashed vertical lines show the quarter of Chapter 13 flag removal and the quarter of Chapter 7 flag removal, which occurs 3 years later. Outcomes are normalized to the average value of the outcome for Chapter 13 filers in the quarter prior to flag removal. The sample includes Chapter 13 and Chapter 7 filers who were age 30-54 at the time of Chapter 13 flag removal, successfully completed the bankruptcy process, and had their bankruptcy flag removed sometime between 2002-2011. See the Table 1 notes for additional details on the outcome measures and sample. 


\section{Figure A6: Dose-Response}

(A) Credit Card Limits

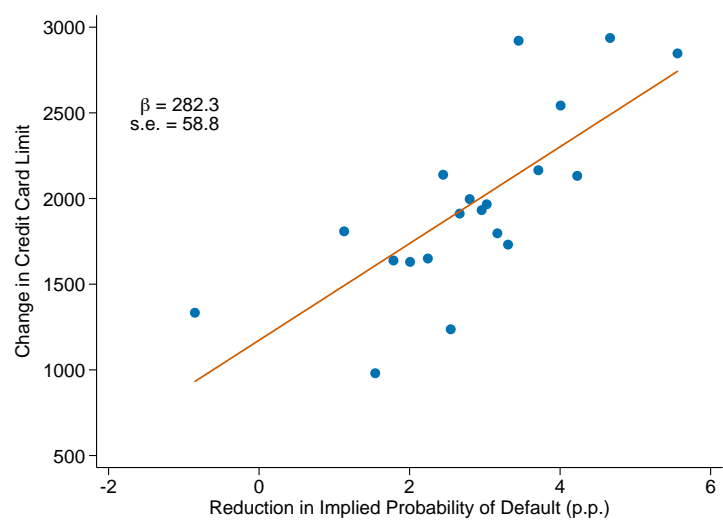

(B) Credit Card Balances

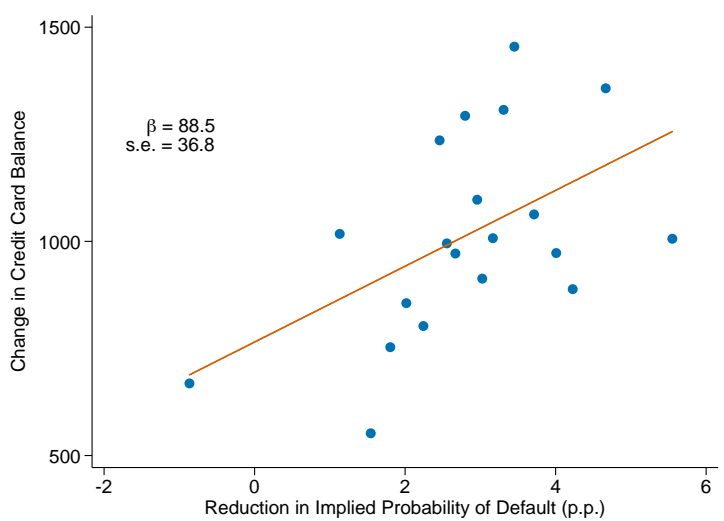

Note: This figure shows binned scatter plots of the estimated coefficients from difference-in-differences regressions conducted at the age group $\times$ state group level. Panel A plots the dollar increase in credit card limits against the estimated reduction in the implied probability of default. Panel B plots the dollar increase in credit card balances against the estimated reduction in the implied probability of default. The solid line shows the best linear fit estimated on the underlying age-by-state level data weighted by the number of observations within each group. The coefficients show the estimated slope of the best-fit line, with standard errors clustered at the state level reported below. The effects on employment and credit limits are at one year after flag removal. See the text for additional details on the specification. 


\section{Figure A7: Credit Card Balance by Pre-Flag Removal Credit Score}

(A) Bottom Quartile

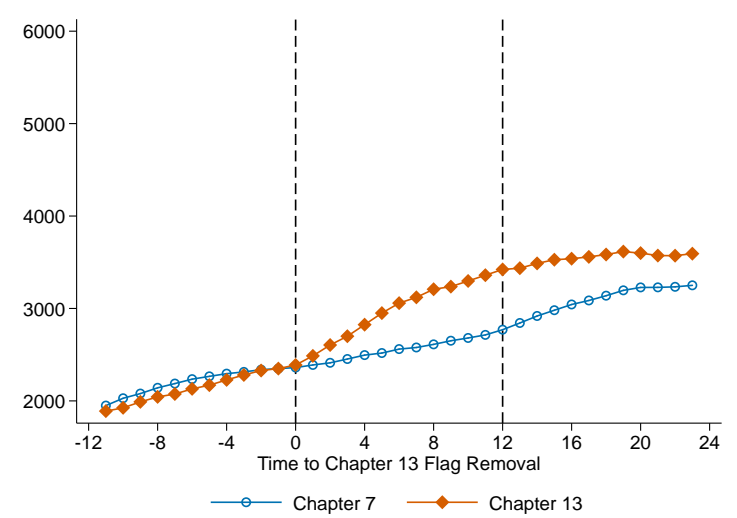

(C) Third Quartile

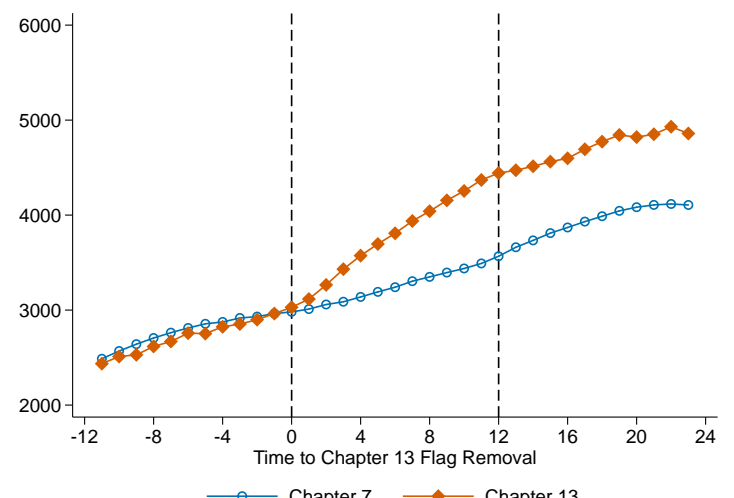

(B) 2nd Quartile

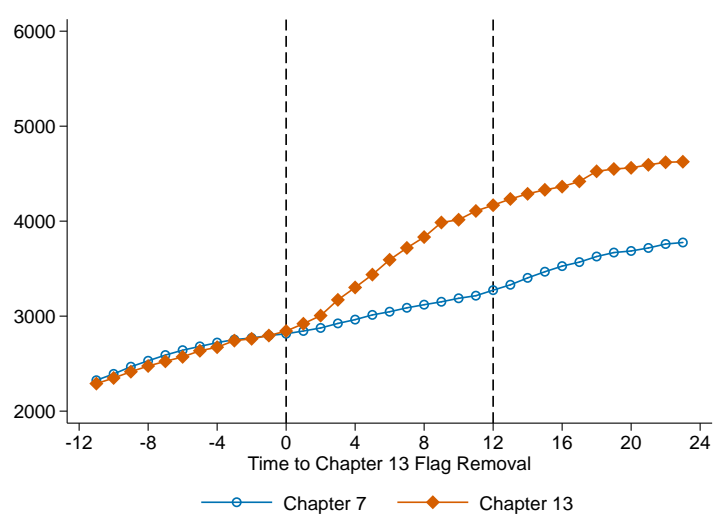

(D) Top Quartile

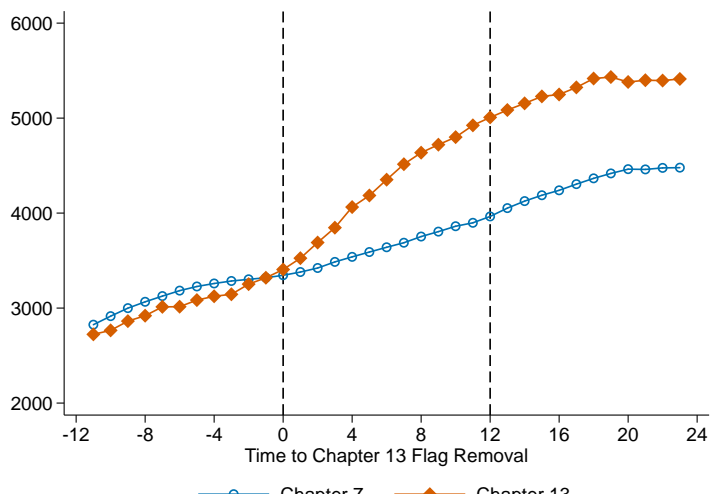

Note: This figure plots average credit card balances for Chapter 13 and Chapter 7 bankruptcy filers by predicted pre-flag removal credit score. We construct pre-removal credit scores from a linear regression of pre-flag removal credit score on five-year age buckets and state fixed effects. The horizontal axis denotes time, in quarters, relative to the quarter of Chapter 13 flag removal, which occurs 7 years after filing. The dashed vertical lines show the quarter of Chapter 13 flag removal and the quarter of Chapter 7 flag removal, which occurs 3 years later. Outcomes are normalized to the average value of the outcome for Chapter 13 filers in the quarter prior to flag removal. The sample includes Chapter 13 and Chapter 7 filers who were age 30-54 at the time of Chapter 13 flag removal, successfully completed the bankruptcy process, and had their bankruptcy flag removed sometime between 2002-2011. See the Table 1 notes for additional details on the outcome measures and sample. 


\section{Figure A8: Effect of Chapter 13 Flag Removal on Mortgage Outcomes}

(A) Mortgage Loan

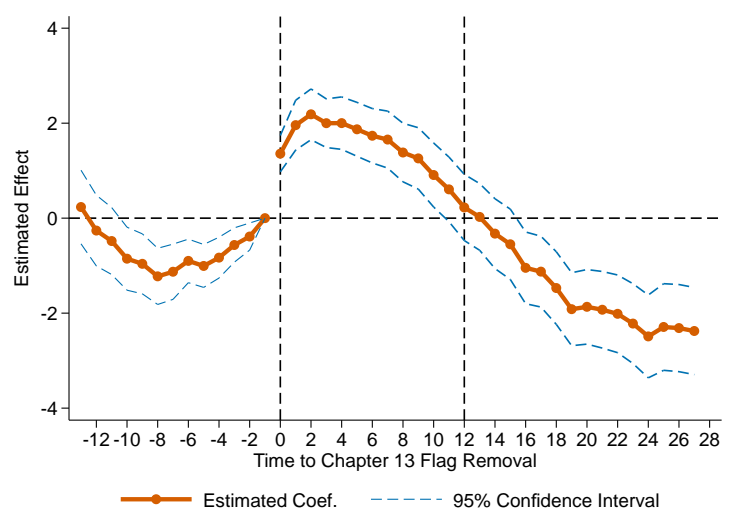

(B) $\log ($ Mortgage Balances +1$)$

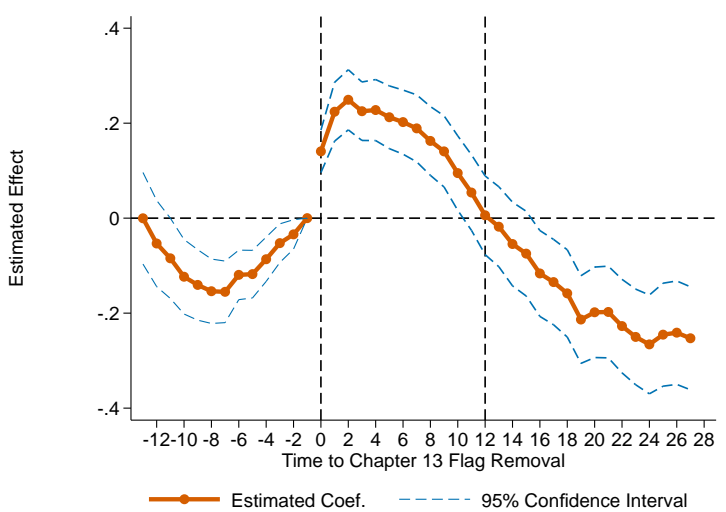

Note: This figure plots difference-in-differences estimates of the effect of Chapter 13 bankruptcy flag removal on mortgage outcomes. The horizontal axis denotes time, in quarters, relative to the quarter of Chapter 13 flag removal, which occurs 7 years after filing. The dashed vertical lines show the quarter of Chapter 13 flag removal and the quarter of Chapter 7 flag removal, which occurs 3 years later. The estimated effect is normalized to zero in the quarter before Chapter 13 flag removal period. The dashed lines are 95 percent confidence intervals from standard errors clustered at the chapter-by-cohort-by-state level. See the text for additional details on the specification and the Table 1 notes for additional details on the outcome measures and sample. 


\section{Figure A9: Mortgage Loan by Pre-Flag Removal Credit Score}

(A) Bottom Quartile

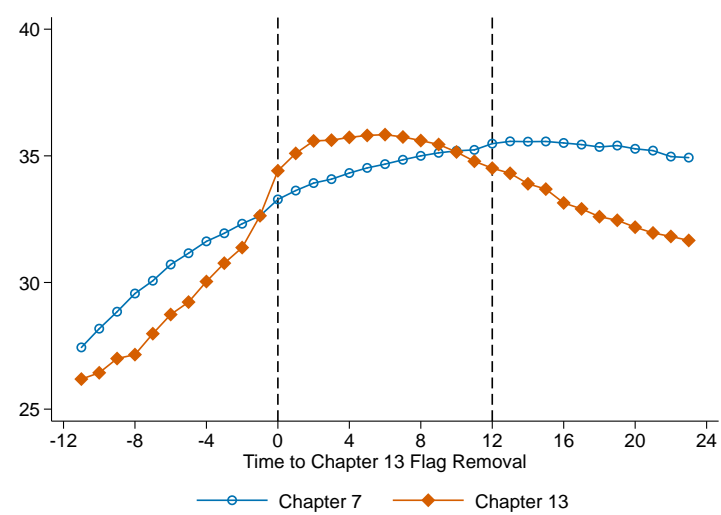

(A) Third Quartile

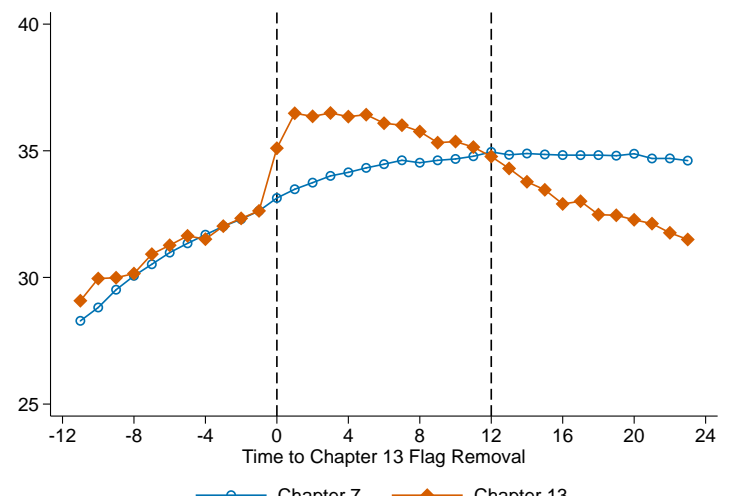

(B) 2nd Quartile

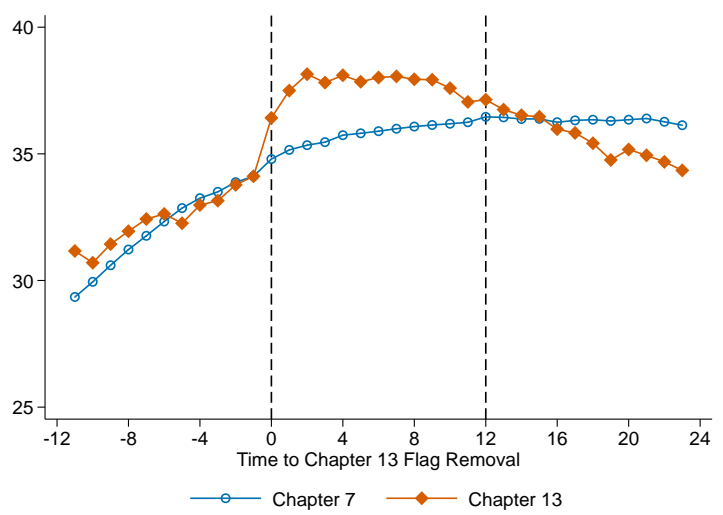

(B) Top Quartile

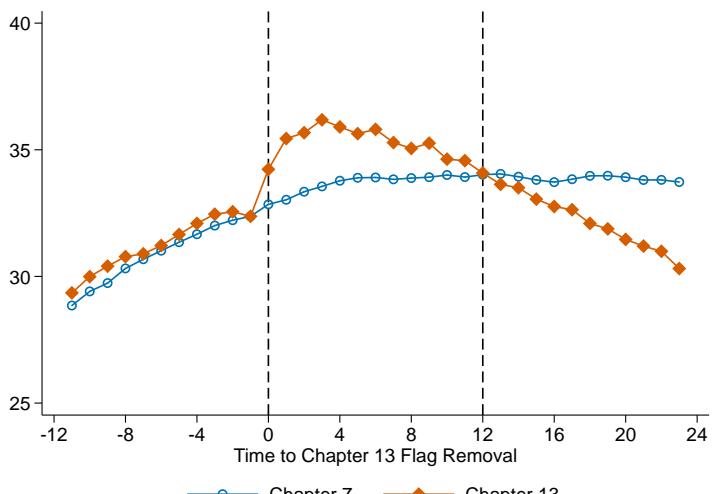

Note: This figure plots average fraction of individuals with a mortgage for Chapter 13 and Chapter 7 bankruptcy filers by predicted pre-flag removal credit score. We construct pre-removal credit scores from a linear regression of pre-flag removal credit score on five-year age buckets and state fixed effects. The horizontal axis denotes time, in quarters, relative to the quarter of Chapter 13 flag removal, which occurs 7 years after filing. The dashed vertical lines show the quarter of Chapter 13 flag removal and the quarter of Chapter 7 flag removal, which occurs 3 years later. Outcomes are normalized to the average value of the outcome for Chapter 13 filers in the quarter prior to flag removal. The sample includes Chapter 13 and Chapter 7 filers who were age 30-54 at the time of Chapter 13 flag removal, successfully completed the bankruptcy process, and had their bankruptcy flag removed sometime between 2002-2011. See the Table 1 notes for additional details on the outcome measures and sample. 


\section{Figure A10: Net Change in Fraction with Mortgage}

(A) All Years

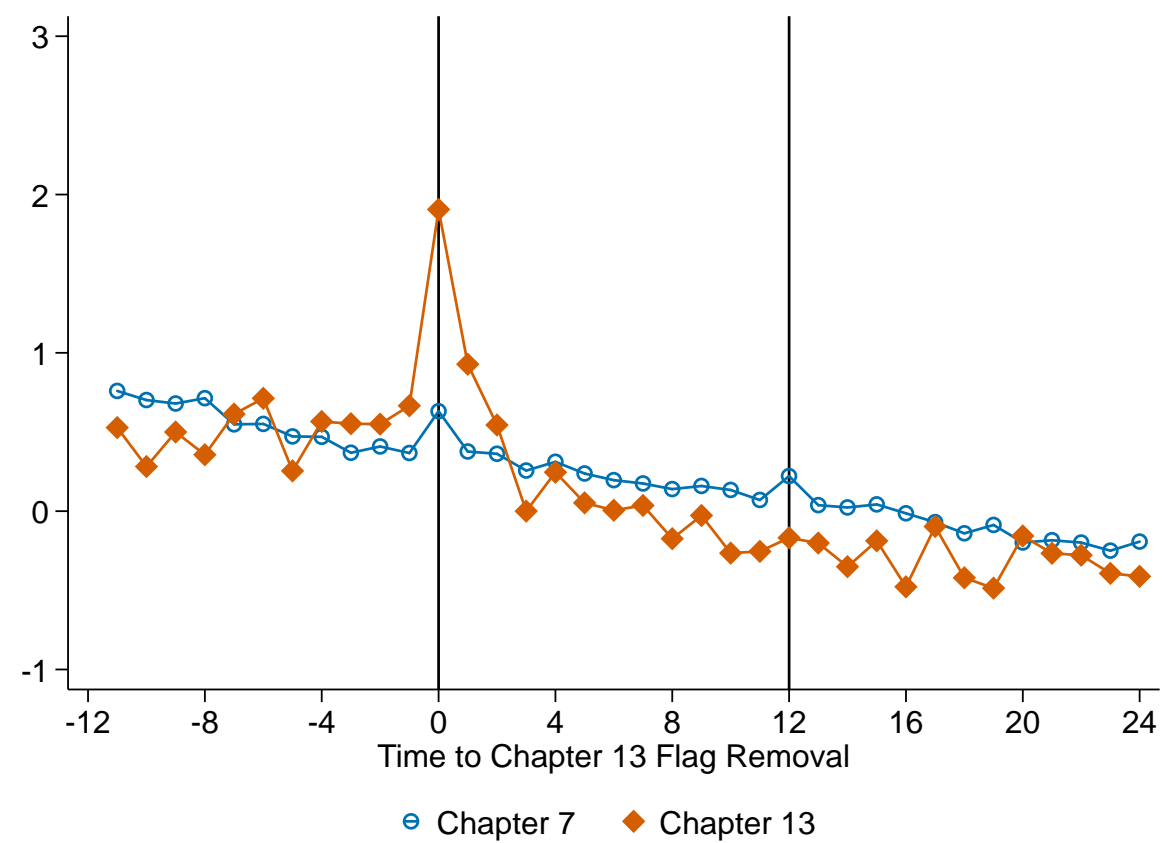

(B) Early (2002-2007)

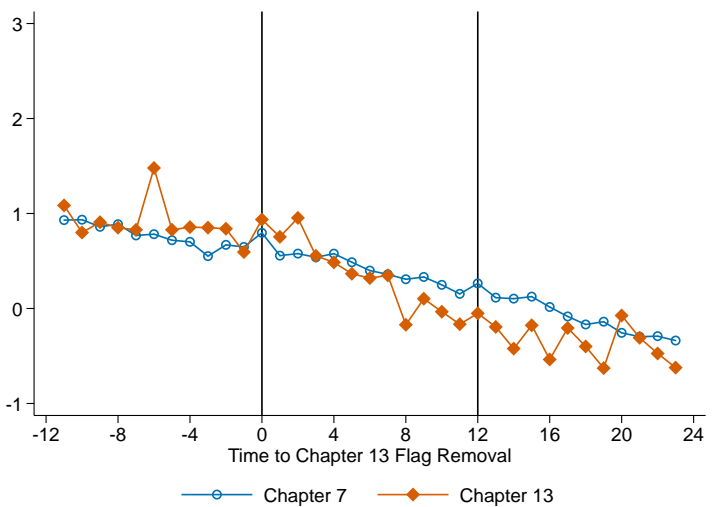

(C) Late (2008-2011)

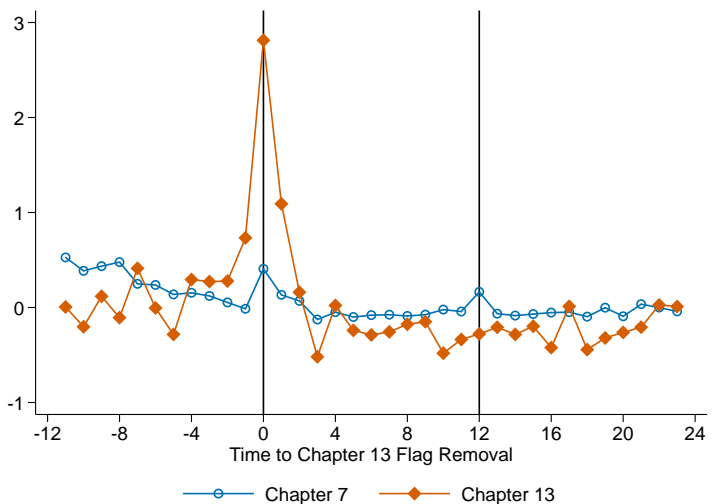

Note: This figure plots the net change in the stock of individuals with a mortgage loan. The net change is calculated as the difference between two objects: the inflow of mortgages, which is the fraction of individuals who go from having no mortgage in the previous quarter to having a mortgage in this quarter; and the outflow of mortgages, which is the fraction of individuals who go from having a mortgage in the previous quarter to having a mortgage in this quarter. Panel A plots this net change for the entire sample. Panel B plots this change for individuals whose flag is removed between 2002 and 2007, inclusive. Panel C plots this change for individuals whose flag is removed between 2008 and 2011, inclusive. 


\section{Figure A11: Effect of Chapter 13 Flag Removal on Labor Market Outcomes}

(A) Wage Employment

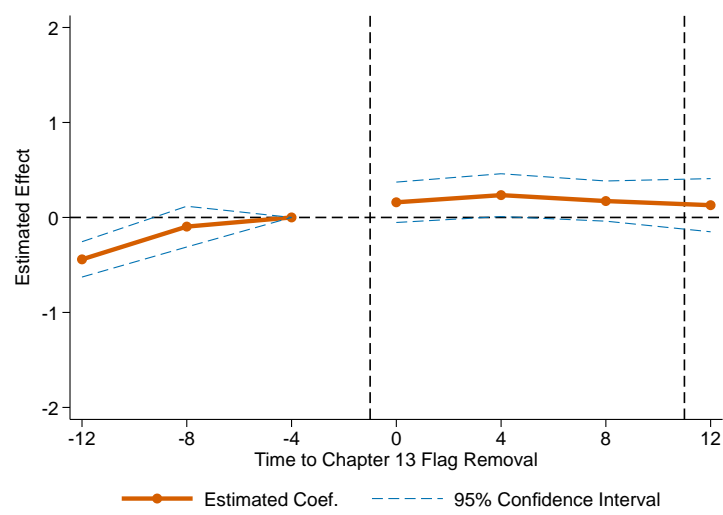

(C) Self Employment

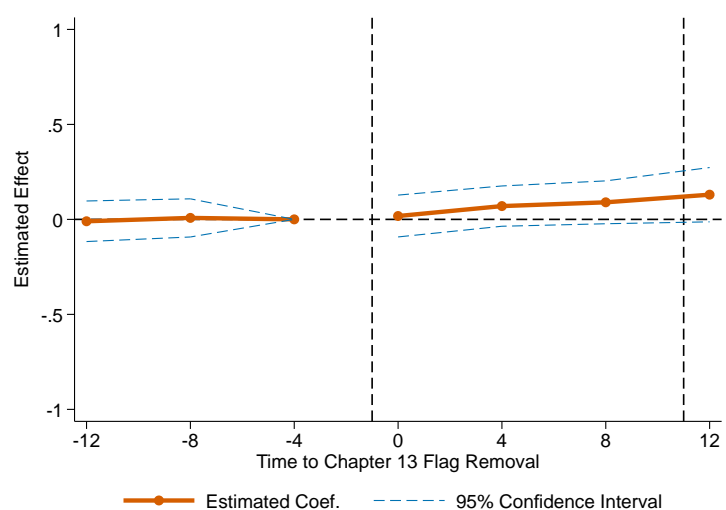

(E) Any Earnings

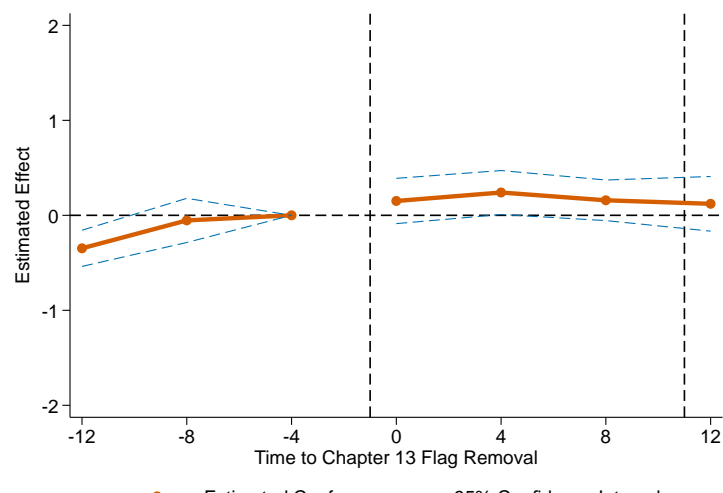

(B) $\log ($ Wage Earnings + 1)

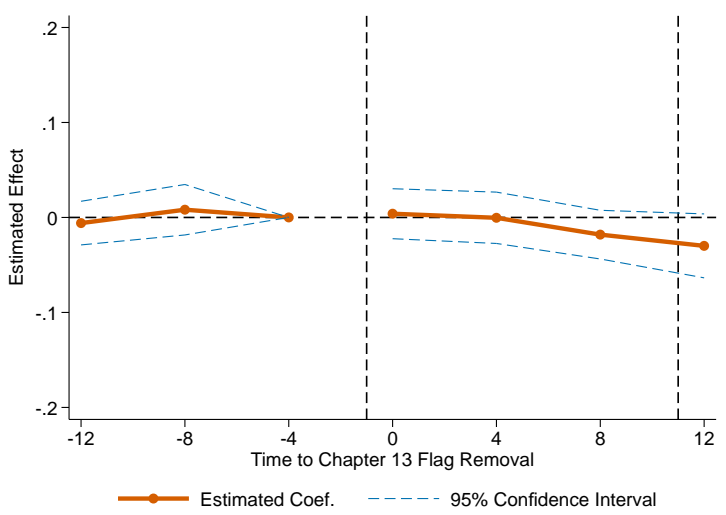

(D) $\log ($ Self Earnings + 1)

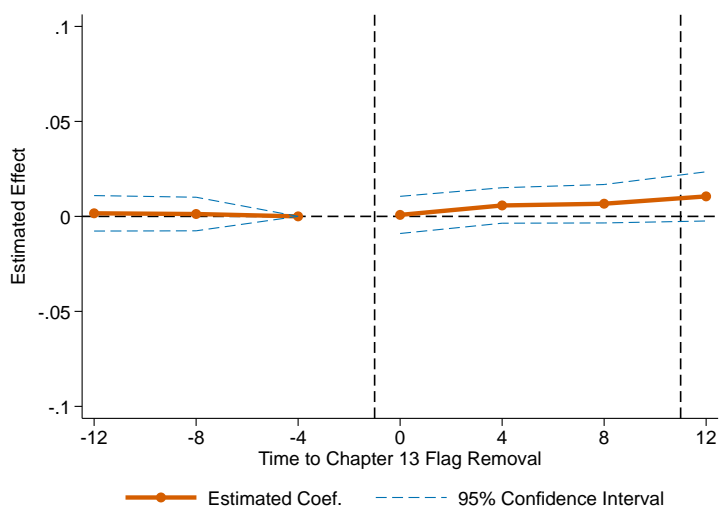

(F) $\log ($ Total Earnings +1$)$

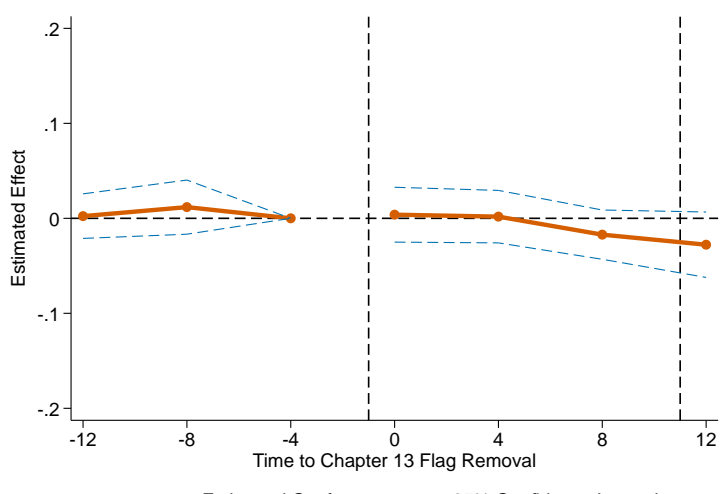

Note: This figure plots difference-in-differences estimates of the effect of Chapter 13 bankruptcy flag removal on labor market outcomes. The horizontal axis denotes time, in quarters, relative to the year of Chapter 13 flag removal, which occurs 7 years after filing. The dashed vertical lines show the year of Chapter 13 flag removal and the year of Chapter 7 flag removal, which occurs 3 years later. The estimated effect is normalized to zero in the year before Chapter 13 flag removal period. The dashed lines are 95 percent confidence intervals from standard errors clustered at the chapter-by-cohort-by-state level. See the text for additional details on the specification and the Table 1 notes for additional details on the outcome measures and sample. 


\section{Figure A12: Effect of Chapter 13 Flag Removal on Labor Market Outcomes by Period}

(A) Employment 2002-2007

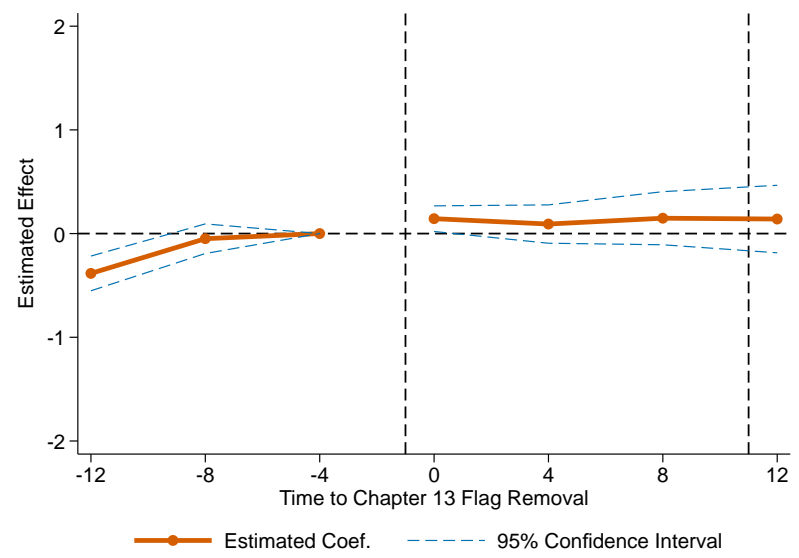

(B) Employment 2008-2011

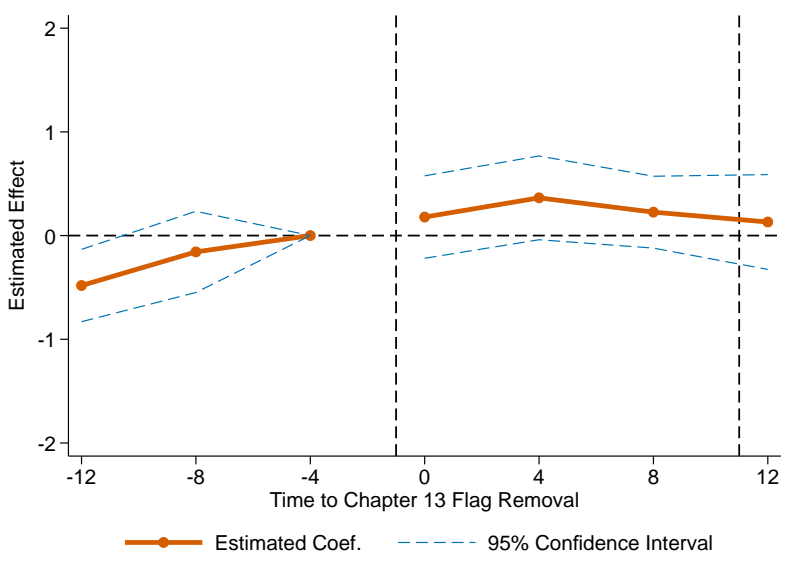

Note: This figure plots difference-in-differences estimates of the effect of Chapter 13 bankruptcy flag removal on labor market outcomes for seperate time periods, 2002-2007 and 2008-2011. The horizontal axis denotes time, in quarters, relative to the year of Chapter 13 flag removal, which occurs 7 years after filing. The dashed vertical lines show the year of Chapter 13 flag removal and the year of Chapter 7 flag removal, which occurs 3 years later. The estimated effect is normalized to zero in the year before Chapter 13 flag removal period. The dashed lines are 95 percent confidence intervals from standard errors clustered at the chapter-by-cohort-by-state level. See the text for additional details on the specification and the Table 1 notes for additional details on the outcome measures and sample. 
Figure A13: Employment Transitions Trends

(A) Change Job

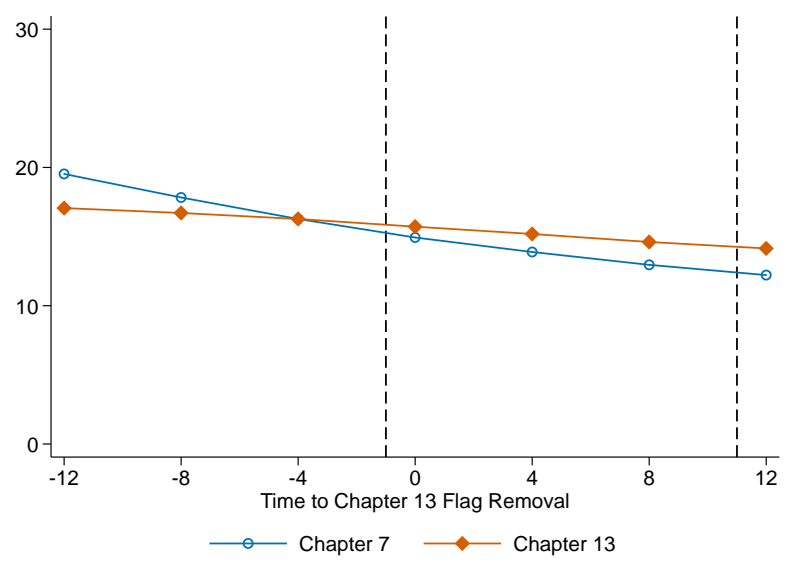

(C) Start Job

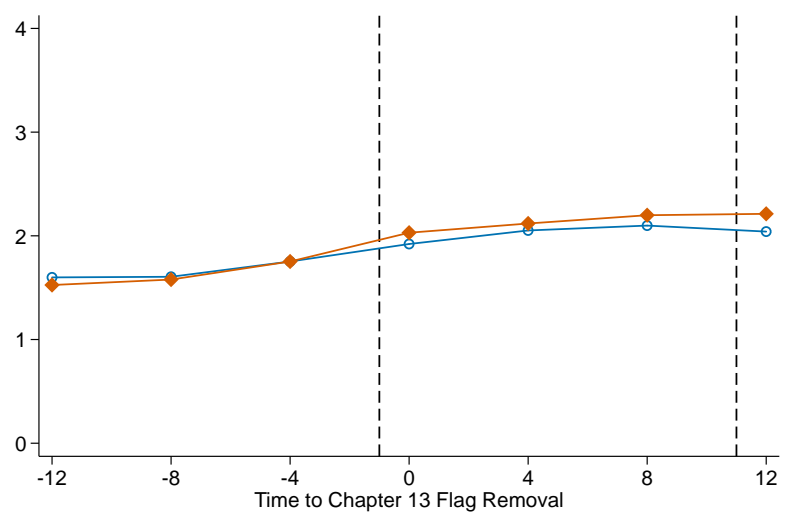

(B) Same Job

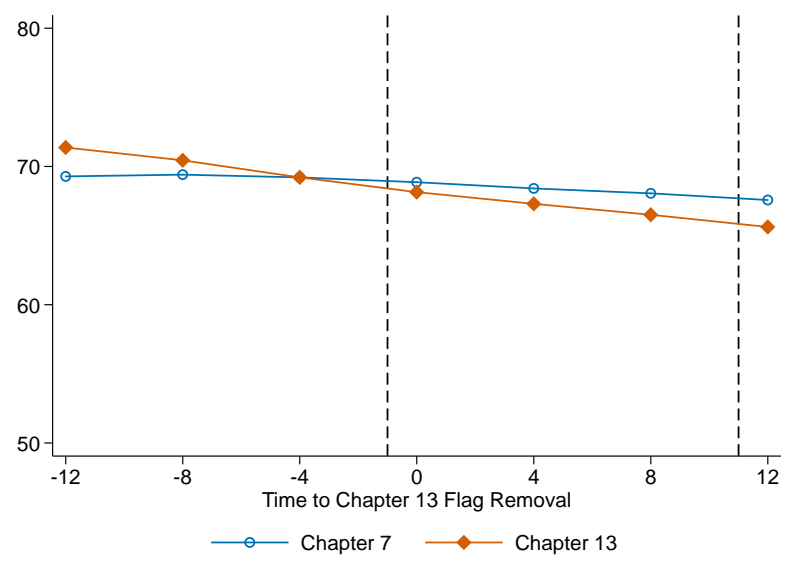

(D) End Job

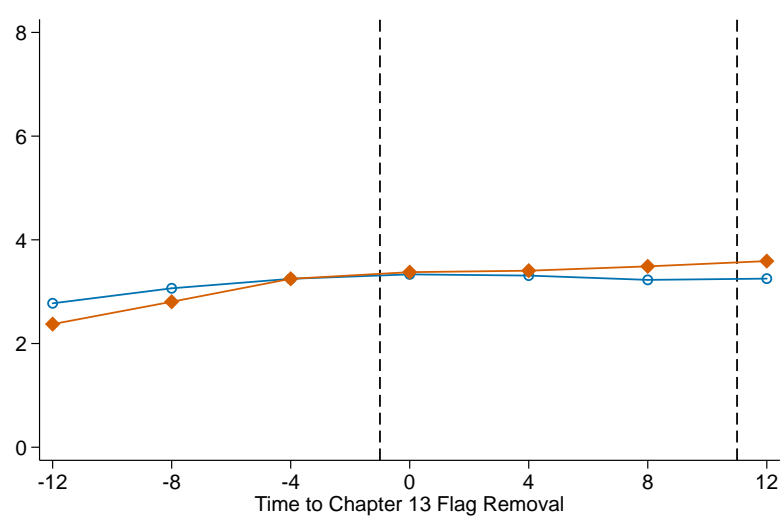

(E) No Job

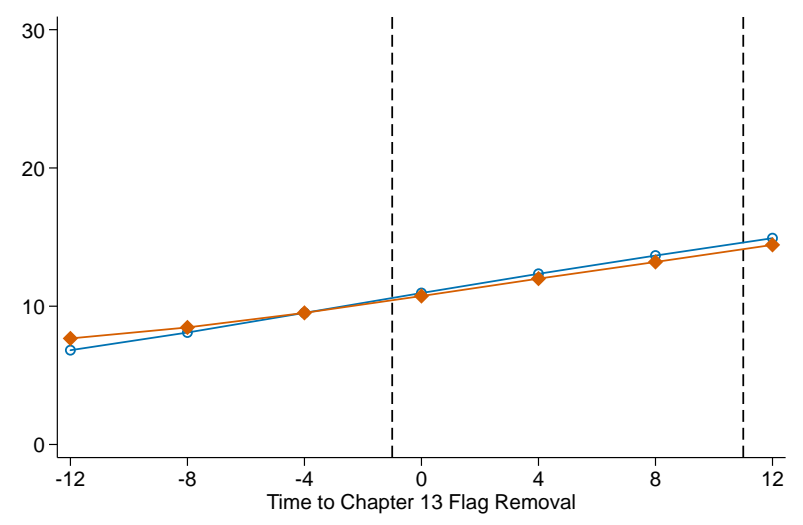

$\longrightarrow$ Chapter $7 \longrightarrow$ Chapter 13

Note: This figure plots the average labor market outcomes of bankruptcy filers to the event of bankruptcy flag removal. The horizontal axis denotes time, in quarters, relative to the year of Chapter 13 flag removal, which occurs 7 years after filing. The dashed vertical lines show the year of Chapter 13 flag removal and the year of Chapter 7 flag removal, which occurs 3 years later. Outcomes are normalized to the average value of the outcome for Chapter 13 filers in the year prior to flag removal. The sample includes Chapter 13 and Chapter 7 filers who were age 30-54 at the time of Chapter 13 flag removal, successfully completed the bankruptcy process, and had their bankruptcy flag removed sometime between 2002-2011. See the Table 1 notes for additional details on the outcome measures and sample. 
Figure A14: Employment by Industry Trends

(A) Missing

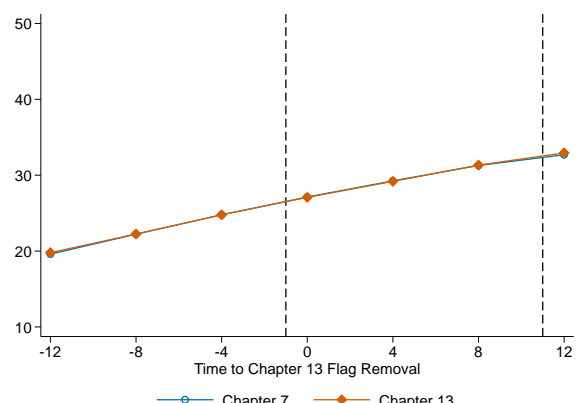

(D) Transportation

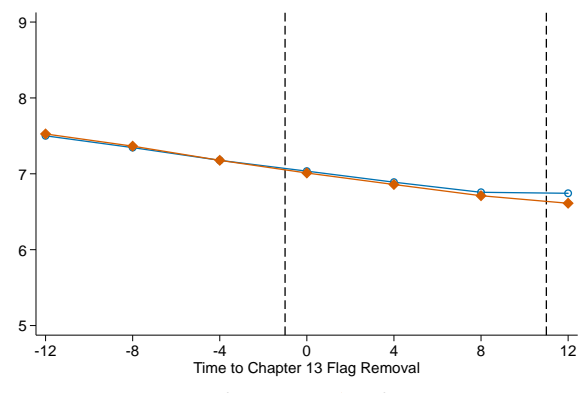

(D) Finance

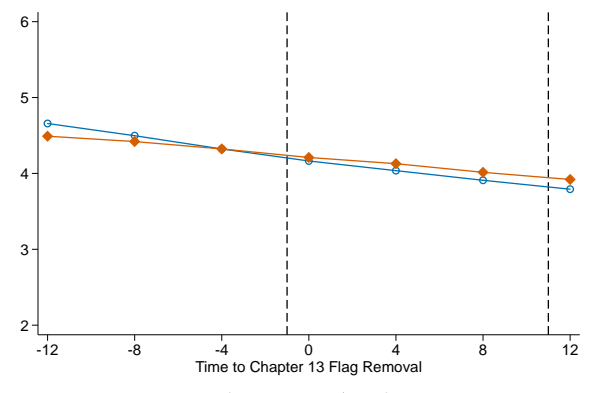

(B) Construction

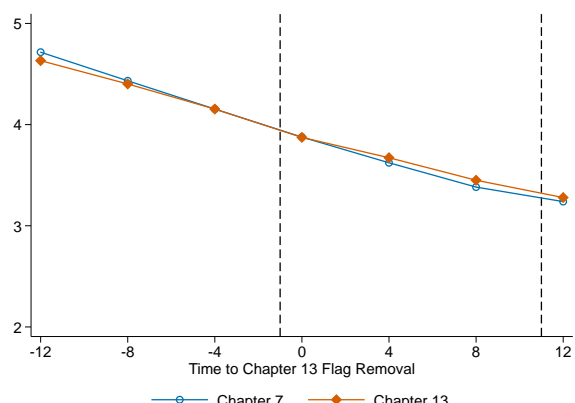

(E) Wholesale

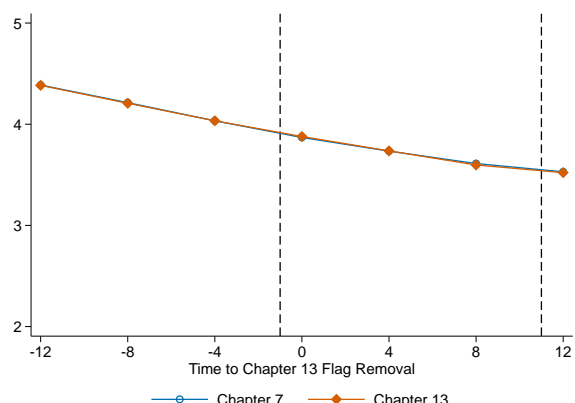

(E) Services

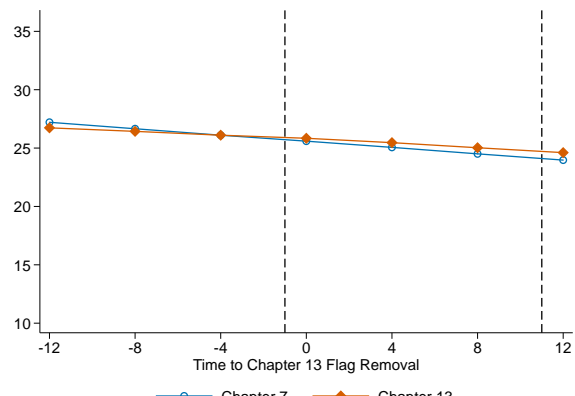

(C) Manufacturing

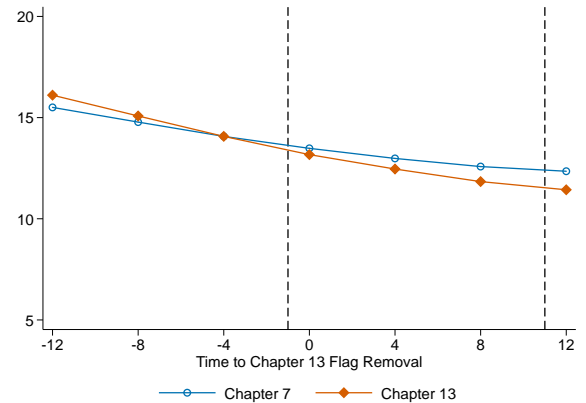

(F) Retail

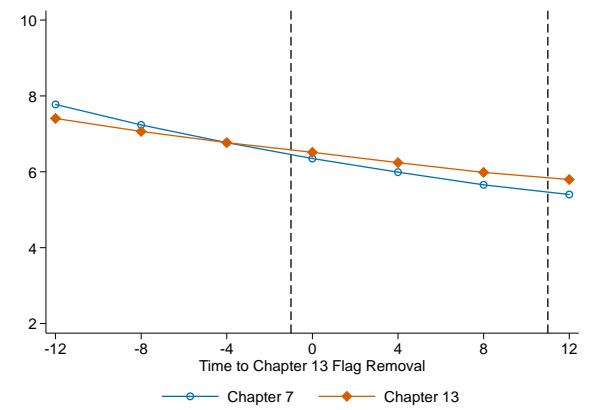

(F) Public

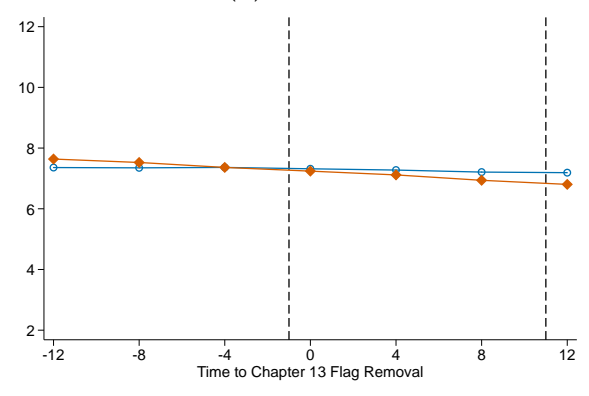

Note: This figure plots the average labor market outcomes of bankruptcy filers to the event of bankruptcy flag removal. The horizontal axis denotes time, in quarters, relative to the year of Chapter 13 flag removal, which occurs 7 years after filing. The dashed vertical lines show the year of Chapter 13 flag removal and the year of Chapter 7 flag removal, which occurs 3 years later. Outcomes are normalized to the average value of the outcome for Chapter 13 filers in the year prior to flag removal. The sample includes Chapter 13 and Chapter 7 filers who were age 30-54 at the time of Chapter 13 flag removal, successfully completed the bankruptcy process, and had their bankruptcy flag removed sometime between 2002-2011. See the Table 1 notes for additional details on the outcome measures and sample. 
Table A1: Credit Results by Pre-Flag Removal Credit Score

\begin{tabular}{|c|c|c|c|c|}
\hline & \multirow{3}{*}{$\begin{array}{c}\text { Mean at } \\
t=-1 \\
(1)\end{array}$} & \multicolumn{3}{|c|}{ Difference-in-Differences Estimates } \\
\hline & & 1 Year & 2 Years & 3 Years \\
\hline & & $(2)$ & $(3)$ & (4) \\
\hline \multicolumn{5}{|l|}{ Score Quartile 1: } \\
\hline Credit Score & $\begin{array}{l}578.08 \\
(75.47)\end{array}$ & $\begin{array}{l}7.35^{* * *} \\
(0.57)\end{array}$ & $\begin{array}{c}1.79^{* *} \\
(0.83)\end{array}$ & $\begin{array}{c}-2.14^{* *} \\
(0.88)\end{array}$ \\
\hline Implied Probability of Default & $\begin{array}{c}37.23 \\
(19.62)\end{array}$ & $\begin{array}{c}-2.14^{* * *} \\
(0.18)\end{array}$ & $\begin{array}{r}-0.44^{*} \\
(0.25)\end{array}$ & $\begin{array}{l}0.81^{* * *} \\
(0.27)\end{array}$ \\
\hline Credit Card Limits & $\begin{array}{c}2,032.40 \\
(4023.24)\end{array}$ & $\begin{array}{l}260.59^{* * *} \\
(25.84)\end{array}$ & $\begin{array}{l}660.85^{* * *} \\
(50.26)\end{array}$ & $\begin{array}{l}899.17^{* * *} \\
(69.70)\end{array}$ \\
\hline Credit Card Balance & $\begin{array}{c}1,429.12 \\
(1,478.73)\end{array}$ & $\begin{array}{l}145.92^{* * *} \\
(22.83)\end{array}$ & $\begin{array}{l}438.55^{* * *} \\
(39.88)\end{array}$ & $\begin{array}{l}604.43^{* * *} \\
(47.54)\end{array}$ \\
\hline Mortgage Loan & $\begin{array}{c}37.38 \\
(48.83)\end{array}$ & $\begin{array}{l}1.45^{* * *} \\
(0.31)\end{array}$ & $\begin{array}{l}1.32^{* * *} \\
(0.42)\end{array}$ & $\begin{array}{c}0.24 \\
(0.46)\end{array}$ \\
\hline \multicolumn{5}{|l|}{ Score Quartile 2: } \\
\hline Credit Score & $\begin{array}{l}594.45 \\
(76.77)\end{array}$ & $\begin{array}{l}10.10^{* * *} \\
(0.53)\end{array}$ & $\begin{array}{l}6.80^{* * *} \\
(0.77)\end{array}$ & $\begin{array}{l}3.31^{* * *} \\
(0.93)\end{array}$ \\
\hline Implied Probability of Default & $\begin{array}{c}32.20 \\
(20.01)\end{array}$ & $\begin{array}{l}-2.85^{* * *} \\
(0.17)\end{array}$ & $\begin{array}{c}-1.82^{* * *} \\
(0.24)\end{array}$ & $\begin{array}{c}-0.68^{* *} \\
(0.29)\end{array}$ \\
\hline Credit Card Limits & $\begin{array}{c}2,744.24 \\
(4,819.91)\end{array}$ & $\begin{array}{l}316.40^{* * *} \\
(33.91)\end{array}$ & $\begin{array}{l}906.78^{* * *} \\
(64.44)\end{array}$ & $\begin{array}{c}1,332.98^{* * *} \\
(81.46)\end{array}$ \\
\hline Credit Card Balance & $\begin{array}{c}1,782.36 \\
(1,769.85)\end{array}$ & $\begin{array}{l}104.75^{* * *} \\
(26.84)\end{array}$ & $\begin{array}{l}484.05^{* * *} \\
(50.80)\end{array}$ & $\begin{array}{l}796.01^{* * *} \\
(64.95)\end{array}$ \\
\hline Mortgage Loan & $\begin{array}{c}40.95 \\
(40.59)\end{array}$ & $\begin{array}{l}1.90^{* * *} \\
(0.33)\end{array}$ & $\begin{array}{l}2.20^{* * *} \\
(0.42)\end{array}$ & $\begin{array}{l}1.58^{* * *} \\
(0.49)\end{array}$ \\
\hline \multicolumn{5}{|l|}{ Score Quartile 3: } \\
\hline Credit Score & $\begin{array}{l}605.97 \\
(75.42)\end{array}$ & $\begin{array}{l}9.74^{* * *} \\
(0.58)\end{array}$ & $\begin{array}{l}6.99^{* * *} \\
(0.80)\end{array}$ & $\begin{array}{l}3.95^{* * *} \\
(0.94)\end{array}$ \\
\hline Implied Probability of Default & $\begin{array}{c}28.73 \\
(19.61)\end{array}$ & $\begin{array}{l}-2.60^{* * *} \\
(0.18)\end{array}$ & $\begin{array}{c}-1.78^{* * *} \\
(0.24)\end{array}$ & $\begin{array}{c}-0.79^{* * *} \\
(0.28)\end{array}$ \\
\hline Credit Card Limits & $\begin{array}{c}3,330.31 \\
(5,548)\end{array}$ & $\begin{array}{l}351.95^{* * *} \\
(35.37)\end{array}$ & $\begin{array}{c}1,078.25^{* * *} \\
(72.00)\end{array}$ & $\begin{array}{c}1,558.36^{* * *} \\
(94.11)\end{array}$ \\
\hline Credit Card Balance & $\begin{array}{c}2,014.13 \\
(3,538.32)\end{array}$ & $\begin{array}{l}165.98^{* * *} \\
(33.79)\end{array}$ & $\begin{array}{l}626.05^{* * *} \\
(46.53)\end{array}$ & $\begin{array}{l}960.59^{* * *} \\
(62.96)\end{array}$ \\
\hline Mortgage Loan & $\begin{array}{c}44.34 \\
(49.66)\end{array}$ & $\begin{array}{l}2.44^{* * *} \\
(0.37)\end{array}$ & $\begin{array}{l}1.99^{* * *} \\
(0.47)\end{array}$ & $\begin{array}{l}1.25^{* *} \\
(0.53)\end{array}$ \\
\hline \multicolumn{5}{|l|}{ Score Quartile 4: } \\
\hline Credit Score & $\begin{array}{l}619.56 \\
(75.52)\end{array}$ & $\begin{array}{l}13.72^{* * *} \\
(0.63)\end{array}$ & $\begin{array}{l}11.65^{* * *} \\
(0.90)\end{array}$ & $\begin{array}{l}9.12^{* * *} \\
(1.08)\end{array}$ \\
\hline Implied Probability of Default & $\begin{array}{c}24.65 \\
(19.36)\end{array}$ & $\begin{array}{c}-3.33^{* * *} \\
(0.19)\end{array}$ & $\begin{array}{c}-2.59^{* * *} \\
(0.26)\end{array}$ & $\begin{array}{c}-1.89^{* * *} \\
(0.31)\end{array}$ \\
\hline Credit Card Limits & $\begin{array}{c}4,221.57 \\
(7,162.69)\end{array}$ & $\begin{array}{l}599.43^{* * *} \\
(52.33)\end{array}$ & $\begin{array}{c}1,561.89^{* * *} \\
(101.34)\end{array}$ & $\begin{array}{c}1,920.18^{* * *} \\
(129.35)\end{array}$ \\
\hline Credit Card Balance & $\begin{array}{c}2,446.28 \\
(4,812.20)\end{array}$ & $\begin{array}{l}230.59^{* * *} \\
(42.15)\end{array}$ & $\begin{array}{l}781.44^{* * *} \\
(68.24)\end{array}$ & $\begin{array}{c}1,067.64^{* * *} \\
(89.02)\end{array}$ \\
\hline Mortgage Loan & $\begin{array}{l}44.6657 \\
(49.73)\end{array}$ & $\begin{array}{l}1.88^{* * *} \\
(0.38)\end{array}$ & $\begin{array}{l}1.89^{* * *} \\
(0.48)\end{array}$ & $\begin{array}{l}1.08^{* *} \\
(0.54)\end{array}$ \\
\hline
\end{tabular}


Note: This table reports difference-in-differences estimates of the effect of Chapter 13 bankruptcy flag removal by predicted pre-flag removal credit score. We construct pre-removal credit scores from a linear regression of pre-flag removal credit score on five-year age buckets and state fixed effects. Column 1 reports the dependent variable mean and standard deviation for Chapter 13 filers in the quarter prior to flag removal. Columns 24 report coefficients on the effect of flag removal from 0-3, 4-7, and 8-11 quarters, respectively. The sample includes Chapter 13 and Chapter 7 filers who were age 30-54 at the time of Chapter 13 flag removal, successfully completed the bankruptcy process, and had their bankruptcy flag removed sometime between $2002-2011$. The regressions include 23,772,930 person-year-quarter observations for 401,469 unique individuals. Standard errors, in parentheses, are clustered at the chapter-by-cohort-year-by-state level. ${ }^{* * *}=$ significant at 1 percent level, ${ }^{* *}=$ significant at 5 percent level, ${ }^{*}=$ significant at 10 percent level. See the text for additional details on the specification and the Table 1 notes for additional details on the outcome measures and sample. 
Table A2: Labor Results by Time Period

\begin{tabular}{|c|c|c|c|c|}
\hline & \multirow{2}{*}{$\begin{array}{c}\text { Mean at } \\
t=-1\end{array}$} & \multicolumn{3}{|c|}{ Difference-in-Differences Estimates } \\
\hline & & 1 Year & 2 Years & 3 Years \\
\hline & (1) & (2) & (3) & $(4)$ \\
\hline Wage Employment 2002-2007 & $\begin{array}{c}83.09 \\
(19.50)\end{array}$ & $\begin{array}{c}0.14^{* *} \\
(0.06)\end{array}$ & $\begin{array}{c}0.09 \\
(0.09)\end{array}$ & $\begin{array}{c}0.15 \\
(0.13)\end{array}$ \\
\hline Wage Employment 2008-2011 & $\begin{array}{c}80.93 \\
(20.23)\end{array}$ & $\begin{array}{c}0.18 \\
(0.20)\end{array}$ & $\begin{array}{c}0.36^{*} \\
(0.20)\end{array}$ & $\begin{array}{c}0.23 \\
(0.17)\end{array}$ \\
\hline
\end{tabular}

Note: This table reports difference-in-differences estimates of the effect of Chapter 13 bankruptcy flag removal on labor market outcomes in two time periods: 2002-2007 and 2008-2011. Column 1 reports the dependent variable mean and standard deviation for Chapter 13 filers in the year prior to flag removal. Columns 2-4 report coefficients on the effect of flag removal for years 1-3. The sample includes Chapter 13 and Chapter 7 filers who were age 30-54 at the time of Chapter 13 flag removal, successfully completed the bankruptcy process, and had their bankruptcy flag removed sometime between 2002-2011. The regressions include 32,797,030 person-year observations for 4,691,675 unique individuals. Standard errors, in parentheses, are clustered at the chapter-by-

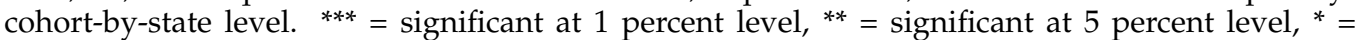
significant at 10 percent level. See the text for additional details on the specification and the Table 1 notes for additional details on the outcome measures and sample. 
Table A3: Effect of Chapter 13 Flag Removal on Employment Transitions

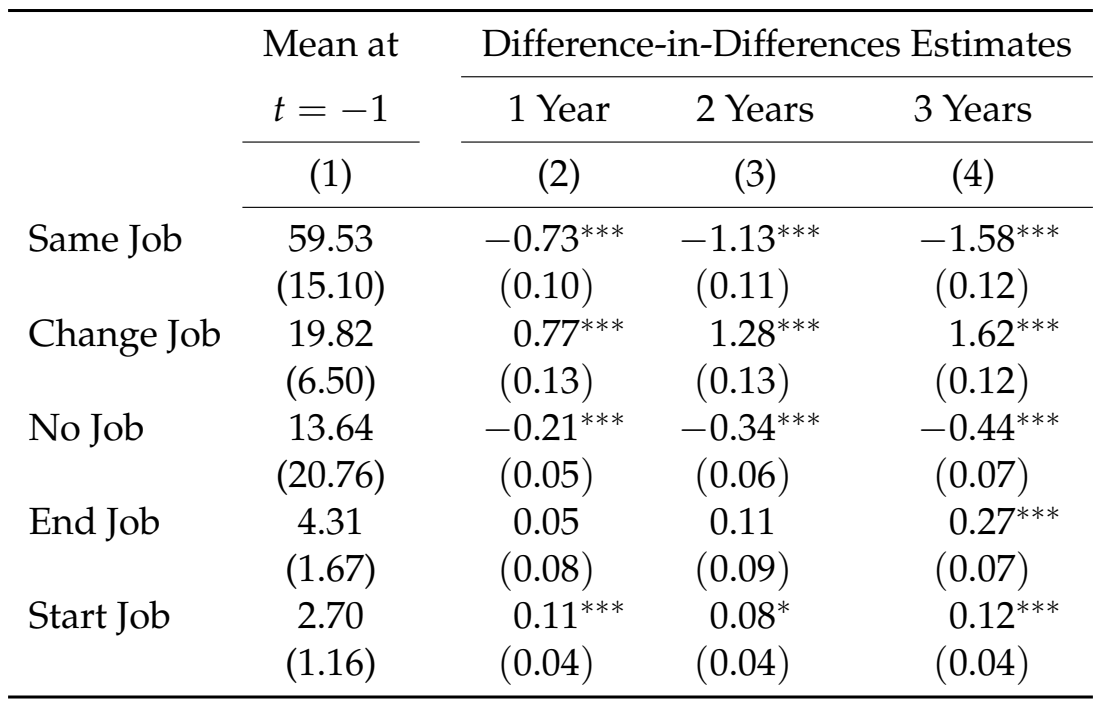

Note: This table reports difference-in-differences estimates of the effect of Chapter 13 bankruptcy flag removal on labor market job transitions. Column 1 reports the dependent variable mean and standard deviation for Chapter 13 filers in the year prior to flag removal. Columns 2-4 report coefficients on the effect of flag removal for years 13. The sample includes Chapter 13 and Chapter 7 filers who were age 30-54 at the time of Chapter 13 flag removal, successfully completed the bankruptcy process, and had their bankruptcy flag removed sometime between 2002-2011. The regressions include $32,797,030$ person-year observations for 4,691,675 unique individuals. Standard errors, in parentheses, are clustered at the chapter-by-cohort-by-state level. ${ }^{* * *}=$ significant at 1 percent level, ${ }^{* *}=$ significant at 5 percent level, ${ }^{*}=$ significant at 10 percent level. See the text for additional details on the specification and the Table 1 notes for additional details on the outcome measures and sample. 
Table A4: Employment Results By Industry

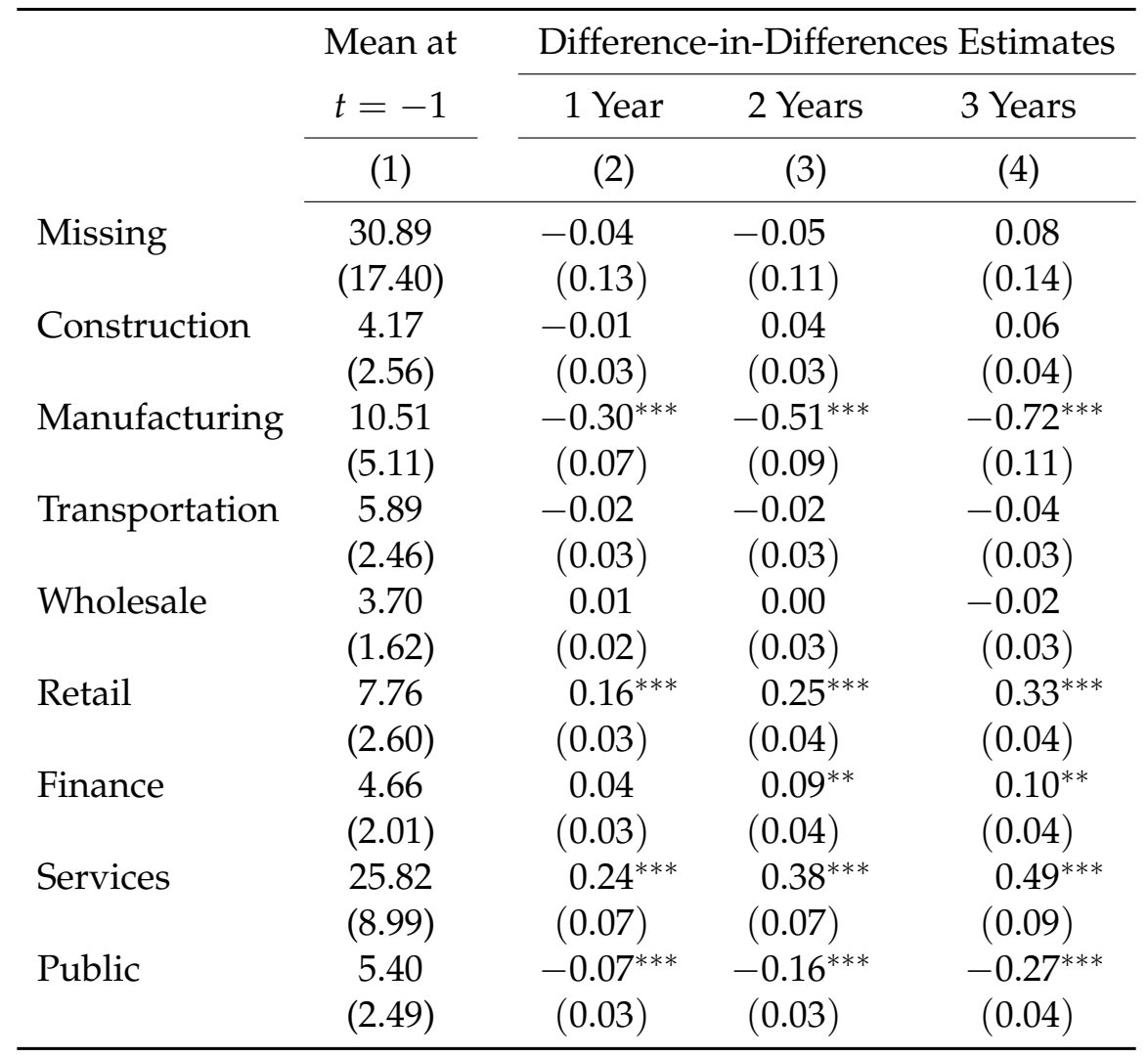

Note: This table reports difference-in-differences estimates of the effect of Chapter 13 bankruptcy flag removal on labor market outcomes in each industry. Column 1 reports the dependent variable mean and standard deviation for Chapter 13 filers in the year prior to flag removal. Columns 2-4 report coefficients on the effect of flag removal for years 1-3. The sample includes Chapter 13 and Chapter 7 filers who were age 30-54 at the time of Chapter 13 flag removal, successfully completed the bankruptcy process, and had their bankruptcy flag removed sometime between 2002-2011. The regressions include $32,797,030$ person-year observations for 4,691,675 unique individuals. Standard errors, in parentheses, are clustered at the chapter-by-cohort-by-state level. ${ }^{* * *}=$ significant at 1 percent level, ${ }^{* *}=$ significant at 5 percent level, ${ }^{*}=$ significant at 10 percent level. See the text for additional details on the specification and the Table 1 notes for additional details on the outcome measures and sample. 
Table A5: State Credit Check Bans

\begin{tabular}{lc}
\hline State & Year of Ban \\
\hline Washington & 2007 \\
Hawaii & 2009 \\
California & 2010 \\
Illinois & 2010 \\
Oregon & 2010 \\
Maryland & 2011 \\
Connecticut & 2012 \\
Vermont & 2012 \\
Colorado & 2013 \\
Nevada & 2013 \\
\hline
\end{tabular}

Note: This table lists all states with a law banning employer credit checks. All states except Washington have an exception for the financial industry. See Clifford and Shoag (2016) for additional details. 